\title{
Un fragmento de scagliola del siglo XVII en Borja (Zaragoza): estudio histórico-artístico y petrológico
}

\author{
A 17th century scagliola fragment in Borja (Zaragoza): \\ a historical-artistic and petrological study
}

\section{Rebeca Carretero Calvo y Pilar Lapuente Mercadal}

\section{Universidad de Zaragoza}

Departamento de Historia del Arte e Instituto Universitario de Investigación en Patrimonio y Humanidades. Facultad de Filosofía y Letras

Área de Petrología y Geoquímica del Departamento de Ciencias de la Tierra e Instituto Universitario de Investigación en Patrimonio y Humanidades. Facultad de Ciencias

C/ Pedro Cerbuna, 12. 50009 - Zaragoza

rcc@unizar.es / plapuent@unizar.es

ORCID: https://orcid.org/0000-0002-1754-1597 / https://orcid.org/0000-0002-8321-2396

Fecha de envío: 21/03/2020. Aceptado: 10/07/2020

Referencia: Santander. Estudios de Patrimonio, 3 (2020), pp. 121-152

DOI: https://doi.org/10.22429/Euc2020.sep.03.04

ISSN 2605-4450 (ed. impresa) / ISSN 2605-5317 (digital)

Resumen: Este artículo presenta el estudio histórico-artístico y las conclusiones del análisis petrológico del fragmento de scagliola de finales del siglo XVII custodiado en el Centro de Estudios Borjanos de la Institución "Fernando el Católico" y procedente de la iglesia de San Miguel de Borja (Zaragoza). En el texto se contextualiza la obra, se explica su técnica, se revelan los materiales que la conforman y se atribuye al artista veneciano Ambrosio Mariesque, activo en tierras aragonesas al menos entre 1688 y 1709.

Palabras clave: scagliola; técnica artística; petrología; siglo XVII.

Abstract: This article presents the historical-artistic study and the conclusions of the petrological analysis of the scagliola fragment of the late 17th century kept at the Centro de Estudios Borjanos of the Institution "Fernando el Católico" and from the church of San Miguel de Borja (Zaragoza, Spain). In this study the mentioned artwork is contextualized, its technique is explained and the materials that comprise it are revealed. Its authorship is attributed to the Venetian artist Ambrosio Mariesque, who worked in Aragon at least between 1688 and 1709 .

Keywords: scagliola; artistic technique; petrology; 17 th century.

$$
* * * * *
$$




\section{INTRODUCCIÓN}

Con motivo de la publicación de su sugerente Jardín cerrado. Flora escondida en la Colegiata de Santa María de Borja en 2001', el recordado Javier Delgado dio a conocer un pequeño fragmento de scagliola de $14 \mathrm{~cm}$ de largo por $8 \mathrm{~cm}$ de ancho y 3,7 cm de grosor (Fig. 1), conservado en el Centro de Estudios Borjanos de la Institución "Fernando el Católico" y procedente de la iglesia de San Miguel de Borja (Zaragoza)², hoy sede del Museo Arqueológico de la ciudad. El autor llevó a cabo un examen ocular de la pieza y la entregó a la Dra. Pilar Lapuente, petróloga de la Universidad de Zaragoza, para que la analizara científicamente.

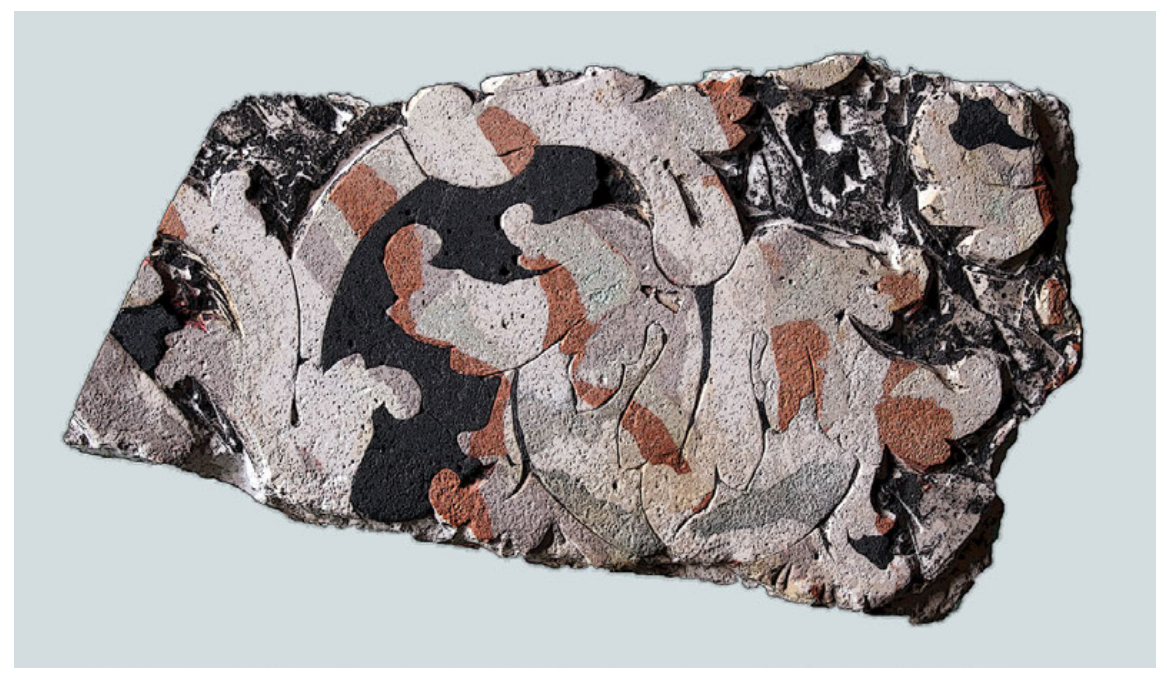

Fig. 1. Fragmento de scagliola. Ambrosio Mariesque (atribuido). H. 1688. Procedente de la iglesia de San Miguel de Borja. Foto Rebeca Carretero

En 2002 la profesora Lapuente tomó una muestra realizando un corte en uno de los laterales del fragmento, la sometió a examen a través de distintas pruebas microscópicas y redactó un detallado informe que quedó inédito $^{3}$. Ahora, en el transcurso de una investigación mayor acerca de la técnica artística de la scagliola en los antiguos territorios de la Corona de Aragón durante los siglos XVII y XVIII, presentamos el estudio histórico-artístico del vestigio, lo contextualizamos y aportamos su análisis petrológico con el

1 DELGADO, Javier, Jardín cerrado. Flora escondida en la colegiata de Santa María de Borja, Borja, Centro de Estudios Borjanos de la Institución "Fernando el Católico", 2001, pp. 81-119.

2 DELGADO, Javier, Jardín cerrado..., pp. 97-99.

3 Las autoras desean agradecer la colaboración del Servicio General de Apoyo a la Investigación SAI, Universidad de Zaragoza. 


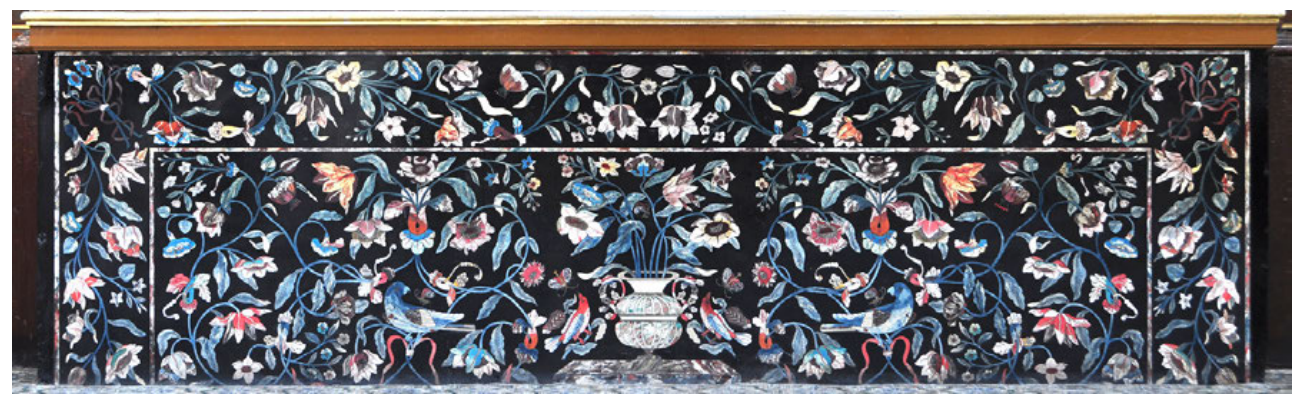

Fig. 2. Frontal del altar mayor. Ambrosio Mariesque. 1688. Colegiata de Santa María de Borja. Foto Jesús Criado

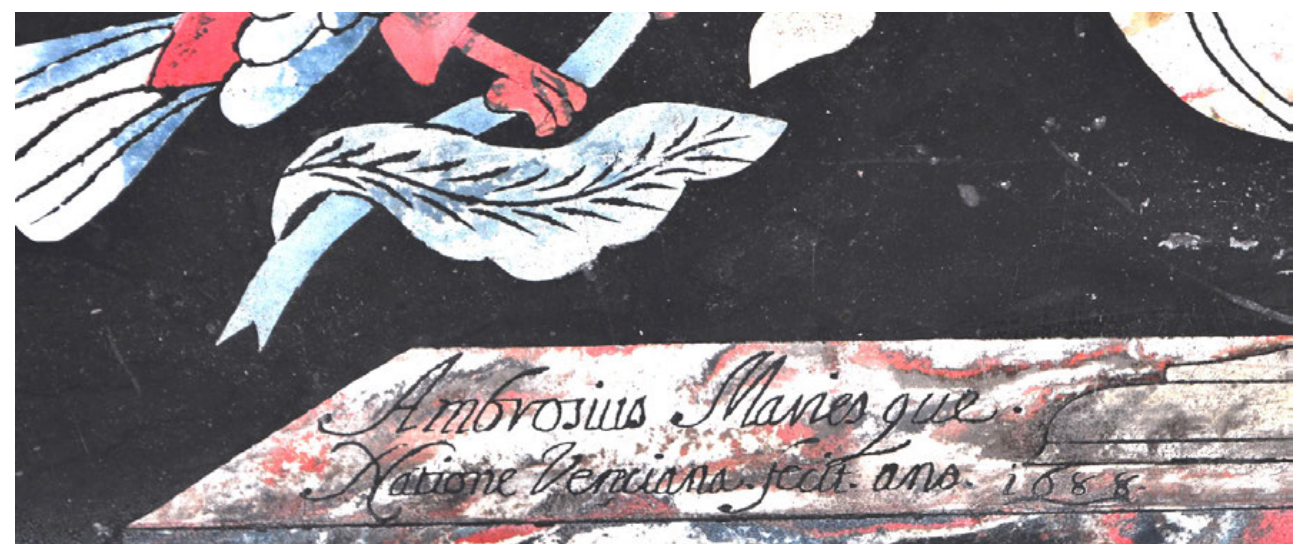

Fig. 3. Detalle de la firma de Ambrosio Mariesque. Frontal del altar mayor. Colegiata de Santa María de Borja. Foto Jesús Criado

objetivo de conocer con todo el detalle posible esta interesante técnica de origen italiano, sus fases de realización y los materiales empleados. De esta manera, abordamos el estudio de este resto artístico desde un punto de vista interdisciplinar.

Aunque fue un joven Manuel Gracia Rivas quien puso a buen recaudo este pequeño fragmento evitando su desaparición a comienzos de la década de 1960, sería Francisco Domínguez Pablo quien lo rescatara en el momento en el que estaba a punto de ser introducido en una hormigonera -junto con el resto de la obra a la que perteneció convertida en escombros- durante la demolición de la antigua iglesia de San Bartolomé de Borja, templo en el que, como explicaremos enseguida, se encontraba ${ }^{4}$.

4 Tal y como se narra en el blog del Centro de Estudios Borjanos de la Institución "Fernando el Católico" [consulta: 06/01/2020], disponible: http://cesbor.blogspot.com/2018/11/una-piezaque-retorna-al-centro.html 
Pese a que se trata de un vestigio de reducidas dimensiones, sus características han permitido ponerlo en relación con el magnífico frontal de altar del retablo mayor de la colegiata de Santa María de Borja (Fig. 2), firmado y fechado en la zona inferior de la propia obra con la inscripción Ambrosius Mariesque./ Natione Veneciana. Fecit. Ano. 1688 (Fig. 3) ${ }^{5}$.

\section{Contexto de la obra}

\section{1. La iglesia de San Miguel de Borja}

Según fray Gregorio de Argaiz, la iglesia de San Miguel ya existía en el siglo XIII pudiendo ser mezquita o templo de los cristianos mozárabes que fue entregado por el rey Jaime I (1213-1276) a los caballeros templarios hasta su desaparición en los primeros años de la centuria siguiente ${ }^{6}$.

Los especialistas han diferenciado varias fases en la construcción del edificio: la primera, fechada a comienzos del siglo XIII, de la que se conserva el ábside semicircular decorado al exterior por modillones de rollo; una segunda etapa, del siglo XIV o principios del XV -que continuó a lo largo de la centuria- que amplió la nave hasta cinco tramos separados por arcos diafragma apuntados que sostendrían una cubierta de madera a dos aguas, y que dotó al templo de cinco capillas laterales -tres en el lado del evangelio dedicadas a San Juan Bautista, San Juan Evangelista y Santiago, y dos en el de la epístola bajo la advocación de Nuestra Señora de las Nieves y San Juan de Porta Latina- y una torre, de la que sólo se levantó el cuerpo inferior ${ }^{7}$; una tercera, del siglo XVI, cuando se decoró el interior del templo con pinturas "a lo romano" 8 ; una cuarta, de principios del siglo XVII, en la que el templo

5 El estado de la cuestión de esta pieza y su "familia" se recoge en CARRETERO CALVO, Rebeca, "'Ambrosius Mariesque venetianus', un maestro de las piedras fingidas en Aragón", en LACARRA DUCAY, Ma del Carmen (coord.), Un olor a Italia. Conexiones e influencias italianas en el arte aragonés (siglos XIV-XVIII), Zaragoza, Institución "Fernando el Católico", 2019, pp. 229-259.

6 ARGAIZ, Gregorio de, Teatro monástico de la Santa Iglesia, ciudad y Obispado de Tarazona, t. VII de La Soledad Laureada por San Benito y sus hijos en las iglesias de España, Madrid, Antonio de Zafra, 1675, pp. 568-569.

7 JIMÉNEZ APERTE, Manuel y ESCRIBANO SÁNCHEZ, José Carlos, “Iglesias medievales en la Comarca de Borja. I", Cuadernos de Estudios Borjanos, VII-VIII (1981), pp. 109-232; GRACIA RIVAS, Manuel, Guía para una visita a la Ciudad de Borja, Borja, Centro de Estudios Borjanos de la Institución Fernando el Católico, 1987, p. 50; y BRESSEL ECHEVERRÍA, Carlos; LOMBA SERRANO, Concepción y MARCO FRAILE, Ricardo, Borja: arquitectura y evolución urbana, Zaragoza, Colegio Oficial de Arquitectos de Aragón, 1988, p. 73.

8 Véase CRIADO MAINAR, Jesús y IBÁÑEZ FERNÁNDEZ, Javier, Sobre campo de azul y carmín. Programas de ornamentación arquitectónica al romano del primer Renacimiento aragonés, Zaragoza, Fundación Teresa de Jesús, 2006, pp. 79-84. 


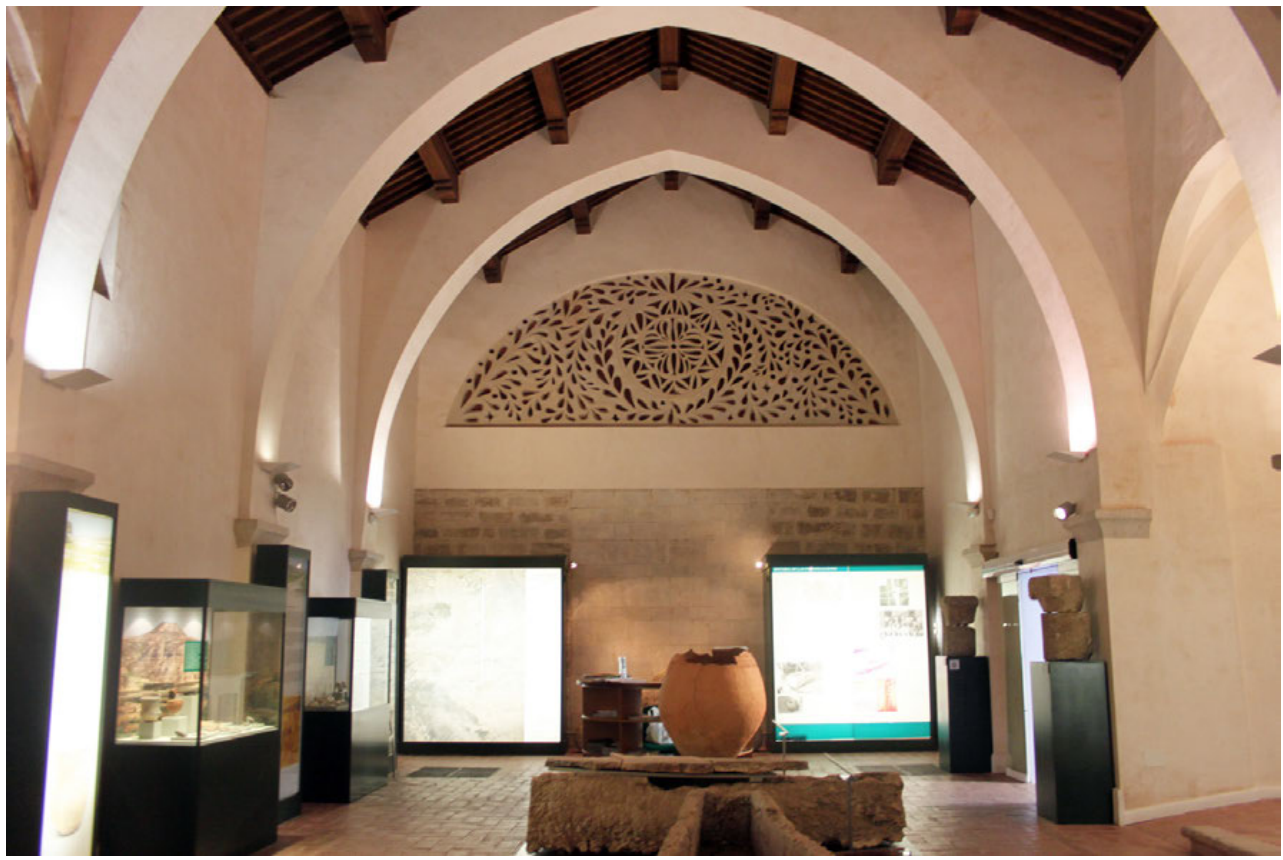

Fig. 4. Vista del interior hacia la zona de los pies. Iglesia de San Miguel de Borja, actual sede del Museo Arqueológico de la ciudad. Foto Rebeca Carretero

pasó a hacer las veces de iglesia del convento de Santa Clara, fundado junto a él, creando un coro alto en el interior de la clausura cerrado con una magnífica celosía calada -ejecutada por los maestros de obras borjanos Domingo de Aroça y Gonzalo Cisneros el 10 de noviembre de 1608- para facilitar la asistencia de las religiosas a los oficios litúrgicos (Fig. 4) ; y una quinta y última etapa llevada a cabo hacia $1692^{10}$, en la que se amplió la nave en un tramo más, se cubrió la techumbre de madera con bóvedas de cañón con lunetos sobre arcos rebajados en la nave, se añadió una imposta corrida a la altura del arranque de las bóvedas (Fig. 5) y se ubicó la entrada en el muro de los pies (Fig. 6) ${ }^{11}$.

9 JIMÉNEZ AZNAR, Emilio, El convento de Santa Clara de Borja (fundación y construcción), Borja, Centro de Estudios Borjanos de la Institución "Fernando el Católico", 2004, doc. no 20, pp. 99-103, esp. p. 101.

10 Para entonces hacía ya prácticamente medio siglo que el convento no usaba esta iglesia. Consúltese JIMÉNEZ AZNAR, Emilio, El convento..., p. 63.

11 GRACIA RIVAS, Manuel, Guía para..., p. 50; BRESSEL ECHEVERRÍA, Carlos; LOMBA SERRANO, Concepción y MARCO FRAILE, Ricardo, Borja: arquitectura..., pp. 73-76; e información de la página web del Sistema de Información del Patrimonio Cultural Aragonés (SIPCA) del Gobierno de Aragón [consulta: 06/01/2020], disponible: http://www.sipca.es/censo/7INM-ZAR-013-055-005/.html\#.XhMNgdI2q70 


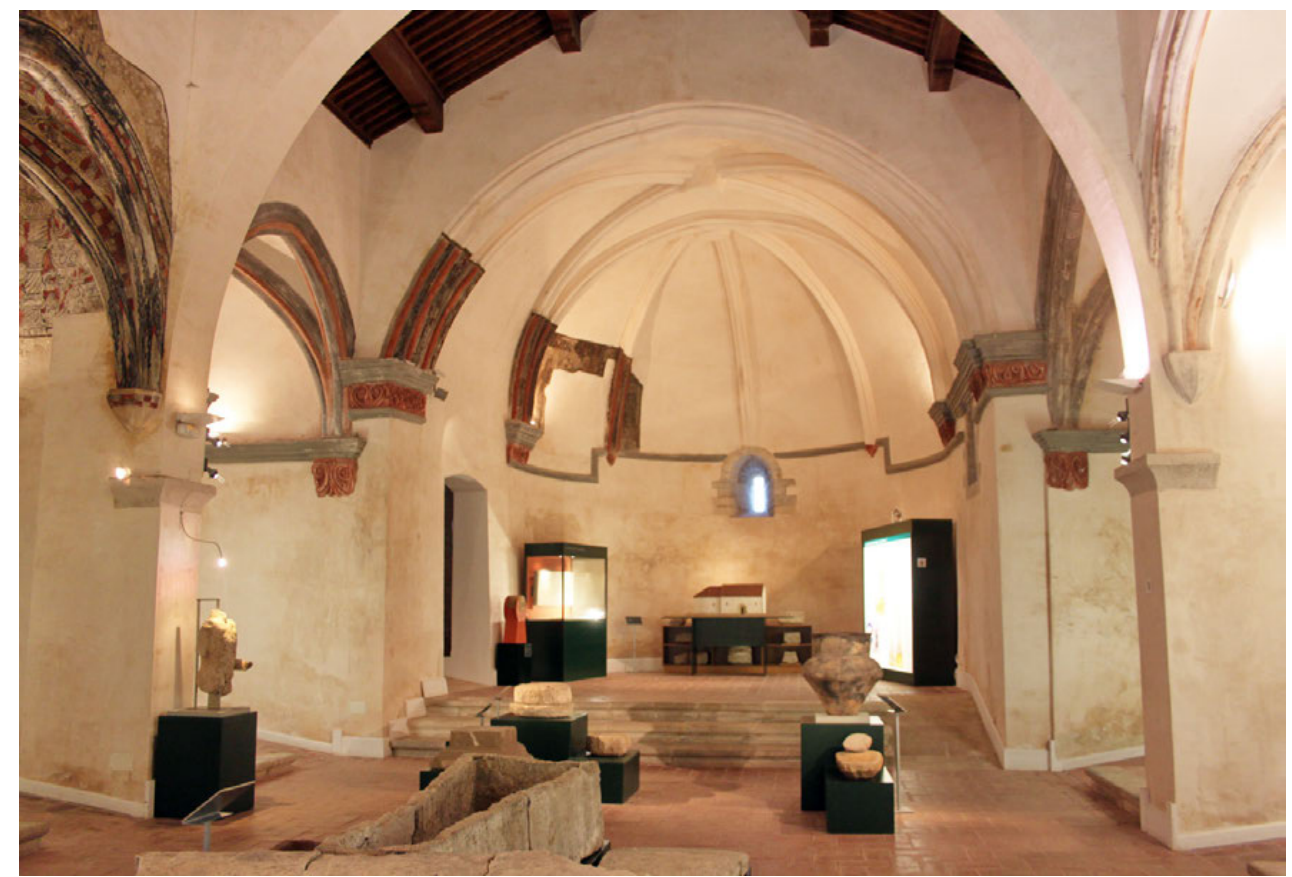

Fig. 5. Vista del interior hacia el ábside. Iglesia de San Miguel de Borja, actual sede del Museo Arqueológico de la ciudad. Foto Rebeca Carretero
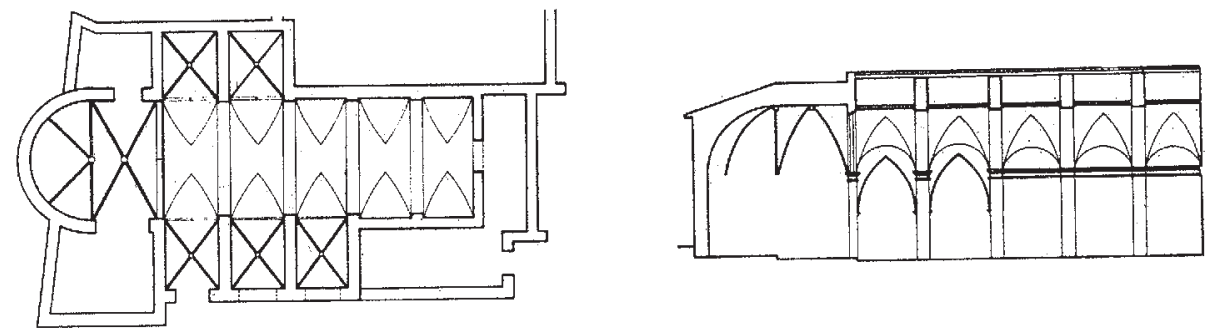

Fig. 6. Planta y alzado de la iglesia de San Miguel de Borja, según Carlos Bressel y Ricardo Marco en 1988

A partir de documentación parroquial, Carlos Bressel, Concepción Lomba y Ricardo Marco aseguraron que en esta última fase se confeccionó un nuevo retablo mayor para el templo que fue colocado en $1692^{12}$, seguramente a la altura de la cornisa que se interrumpe bajo el arco del ábside (Fig. 7). En efecto, el 10 de agosto de 1692 “se pusso el retablo de San Miguel dorado con las limosnas de sus devotos aviendose blanqueado su capilla

12 BRESSEL ECHEVERRÍA, Carlos; LOMBA SERRANO, Concepción y MARCO FRAILE, Ricardo, Borja: arquitectura..., p. 73. 

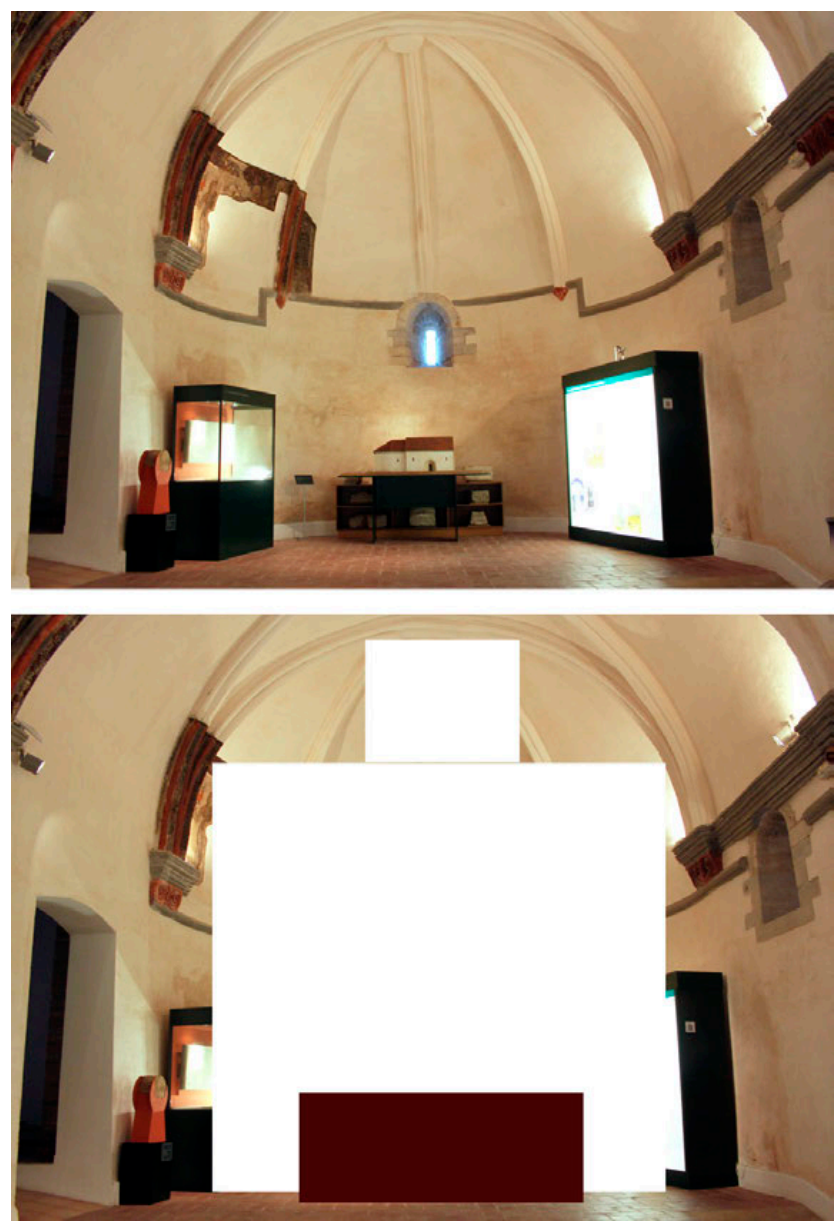

Fig. 7. Vista del ábside y reconstrucción hipotética del volumen del retablo mayor $y$ del frontal de altar. Iglesia de San Miguel de Borja. Foto y elaboración Rebeca

Carretero

para este fin". Unos días más tarde, el 23 del mismo mes, "se hizo lampara nueva y se puso en medio de la iglesia de San Miguel que antes estava en un rincon", mientras que para el día de la festividad del arcángel de ese año "se hicieron 12 candeleros plateados para las fiestas de dicha iglesia"13.

Según el cronista local Rafael García, el jurista Tomás Martínez Galindo, natural de Borja, "mandó construir de su cuenta la imagen y camarín de San Miguel, pues hasta entonces no hubo más que un cuadro en el retablo"14. Asimismo, fue este autor quien, sin revelar tampoco sus fuentes, adjudicó la

13 Archivo de la Colegiata de Santa María de Borja, Quinque libris de la iglesia parrochial de San Miguel de la ciudad de Borja año 1647, f. 3. Agradecemos esta información a la generosidad del Dr. Alberto Aguilera Hernández.

14 GARCÍA, Rafael, Datos cronológicos para la historia de la M. N., M. L. y F. ciudad de Borja, Zaragoza, Tipografía del Hospicio Provincial, 1902, p. 300. Agradecemos a Manuel Gracia, Presidente del Centro de Estudios Borjanos, su inestimable ayuda para localizar esta información. 


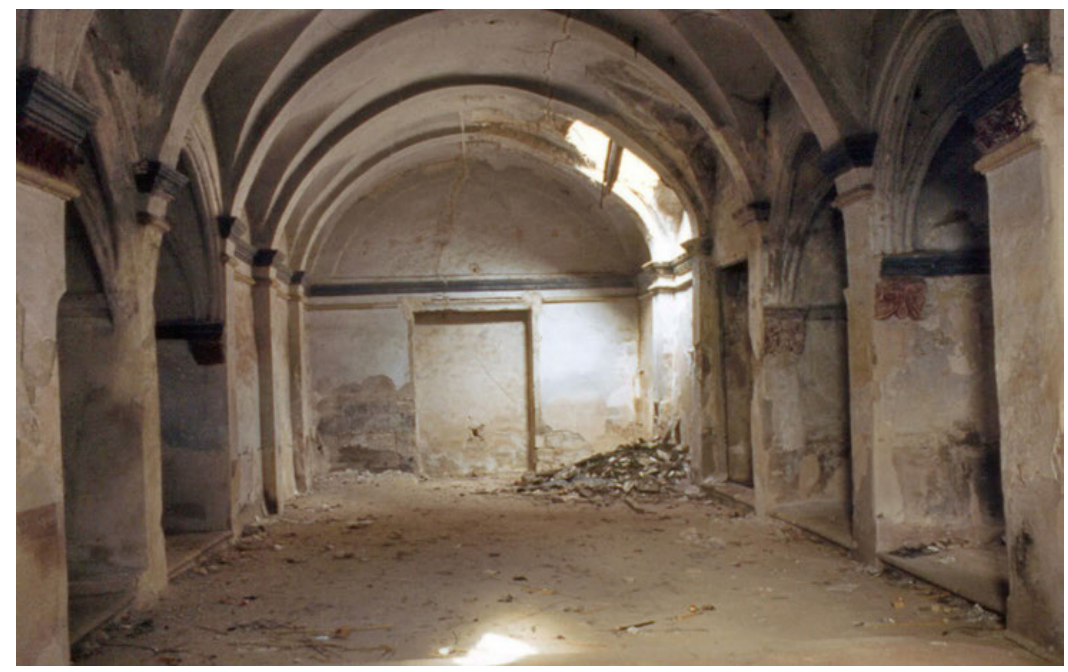

Fig. 8. Imagen retrospectiva del interior hacia la zona de los pies. Iglesia de San Miguel de Borja. Foto Centro de Estudios Borjanos

escultura del arcángel al escultor Simón Lacasa ${ }^{15}$, interesante imagen conservada en la actualidad en el Museo de la Colegiata ${ }^{16}$.

En 1868 la parroquia de San Miguel se anexionó a la de San Bartolomé de la misma localidad ${ }^{17}$. Durante el episcopado de Manuel Hurtado (19471966) el templo quedó desafectado de culto y el Obispado de Tarazona lo alquiló para ser convertido en un almacén del Servicio Nacional de Trigo. En ese momento se desmontaron sus retablos (Fig. 8) y sus bienes muebles fueron trasladados a la iglesia de San Bartolomé. No obstante, poco después este edificio fue demolido y su mobiliario litúrgico -entre el que, como se recordará, se encontraba el de San Miguel- enajenado o destruido ${ }^{18}$, como

15 Rafael García asegura que Lacasa era natural de Borja pero que residía en Huesca (GARCÍA, Rafael, Datos cronológicos..., p. 300). En efecto, Manuel Gracia ha documentado la existencia de un Simón Diego Lacasa Castro, hijo de Diego Lacasa y Rosa Castro, bautizado en la parroquia de San Miguel el 28 de octubre de 1708, que podría identificarse con este artífice (GRACIA RIVAS, Manuel, Diccionario biográfico de personas relacionadas con los veinticuatro municipios del antiguo Partido Judicial de Borja, Borja, Centro de Estudios Borjanos de la Institución "Fernando el Católico", vol. I, 2005, pp. 551-552).

16 GRACIA RIVAS, Manuel, El Museo de la Colegiata, Borja, Centro de Estudios Borjanos de la Institución "Fernando el Católico", 2003, pp. 49-50.

17 BRESSEL ECHEVERRÍA, Carlos; LOMBA SERRANO, Concepción y MARCO FRAILE, Ricardo, Borja: arquitectura..., p. 73.

18 Según se recoge en la página web del SIPCA [consulta: 06/01/2020], disponible: http:// www.sipca.es/censo/7-INM-ZAR-013-055-005/.html\#.XhMNgdI2q70; y en el blog del Centro de Estudios Borjanos [consulta: 06/01/2020], disponible: http://cesbor.blogspot.com/2018/11/ una-pieza-que-retorna-al-centro.html 

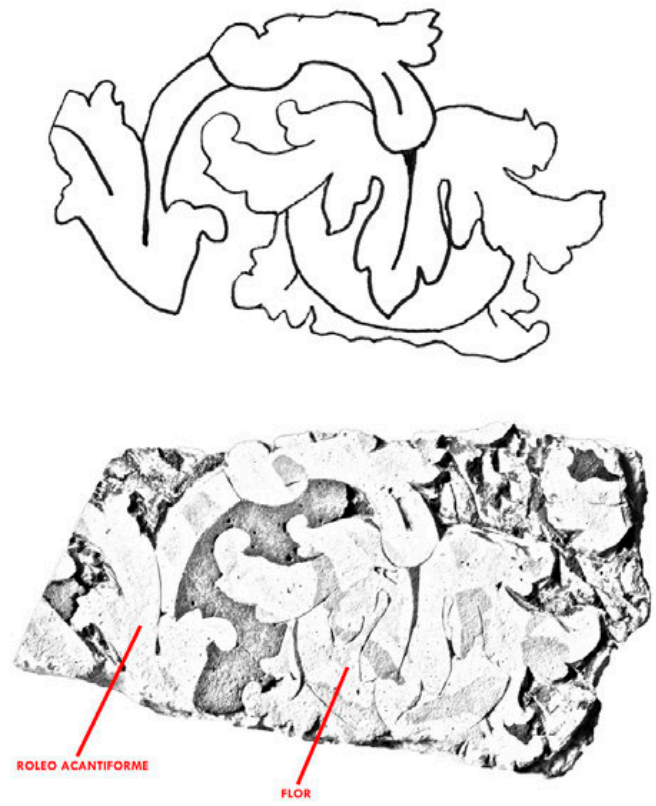

Fig. 9. Diseño decorativo del fragmento de scagliola. Elaboración Rebeca Carretero

fue el caso del frontal de altar al que perteneció el pequeño vestigio que ahora estudiamos.

Entre 1988 y 1999 el Ayuntamiento borjano, con ayuda económica de la Diputación Provincial de Zaragoza, acometió la restauración de la antigua iglesia de San Miguel para albergar el Museo Arqueológico de la ciudad. Esta intervención supuso la desaparición de las bóvedas de época barroca para sacar a la luz la techumbre mudéjar que permanecía oculta sobre ellas ${ }^{19}$.

\section{2. Decoración del fragmento}

El vestigio conservado muestra un motivo decorativo de raigambre vege$\mathrm{tal}^{20}$, en concreto un roleo de acanto con una flor (Fig. 9). Este ornamento se reproducía ya en los primeros paliotti realizados con scagliola en la localidad italiana de Carpi -donde, como expondremos más adelante, se perfeccionó la técnica-, como podemos ver en el frontal del altar de la Addolorata -en la actualidad dedicado a la Assunta- de la catedral carpigiana, confeccionado

19 Información extraída de la página web del SIPCA [consulta: 06/01/2020], disponible: http://www.sipca.es/censo/7-INM-ZAR-013-055-005/.html\#.XhMy9NI2q71. Véase asimismo BRESSEL ECHEVERRÍA, Carlos; LOMBA SERRANO, Concepción y MARCO FRAILE, Ricardo, Borja: arquitectura..., p. 74.

20 Acerca del exorno de este tipo de obras véase CARRETERO CALVO, Rebeca, "Ambrosius Mariesque...", pp. 244-250. 


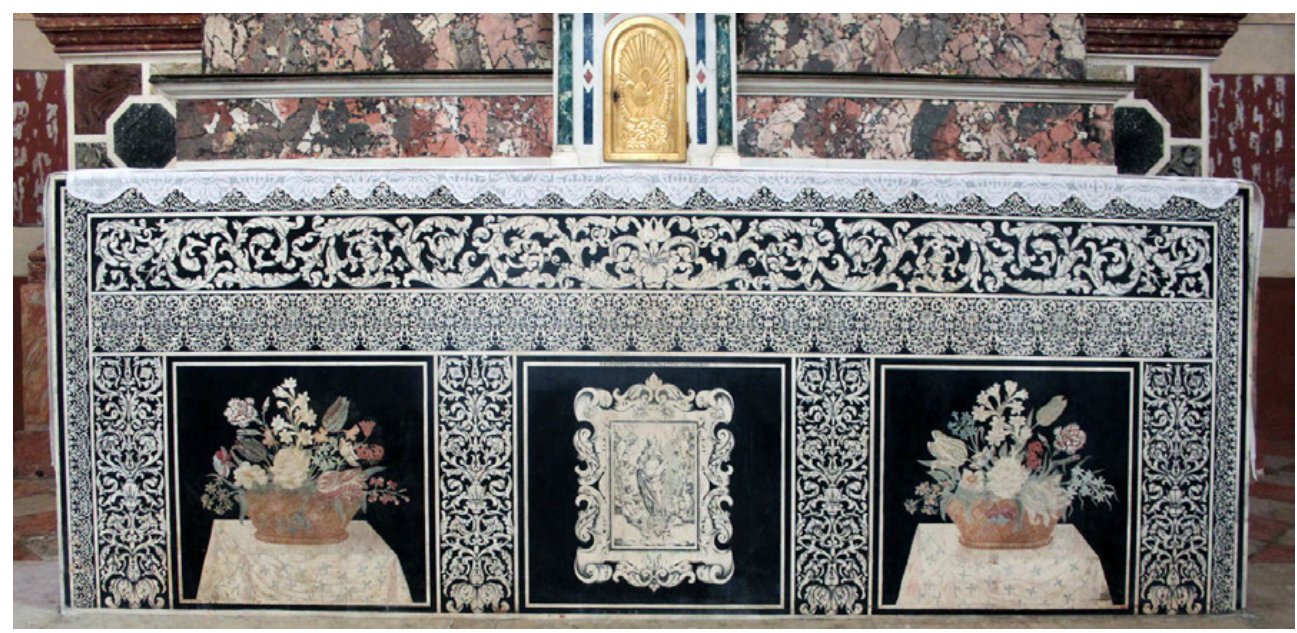

Fig. 10. Frontal del altar de la Addolorata -en la actualidad dedicado a la Assunta-. Catedral de Carpi (Emilia-Romaña). Guido Fassi. 1629. Foto Rebeca Carretero por Guido Fassi en 1629 (Fig. 10)21. Este exorno, primero situado a modo de marco, seguirá desplegándose en el resto de obras efectuadas con esta técnica artística alcanzando un gran desarrollo y movimiento a lo largo de toda la superficie decorativa.

Todo apunta a que la ornamentación de roleos acantiformes apareció por vez primera en el Ara Pacis Augustæ o Altar de la Paz de Augusto, obra maestra construida entre los años 13 y 9 a. C. por voluntad del senado romano para conmemorar la pacificación por el princeps de las provincias de Galia e Hispania.

La estructura exterior está acotada por cuatro pilastras corintias angulares, a las que hay que sumar las que flanquean los accesos en los lados cortos. Cada lado se divide horizontalmente en dos zonas por una greca: las inferiores se decoran con motivos de acanto (Fig. 11) y las superiores con relieves figurativos ${ }^{22}$.

Aunque en el Ara Pacis la frondosa y vigorosa planta de acanto asume el papel de centro generador de la ornamentación en la mayor parte de los paneles ${ }^{23}$, en los paliotti generalmente crea un marco simétrico, dejando el

21 MANNI, Graziano, I Maestri della scagliola in Emilia Romagna e Marche, Módena, Consorzio fra le Banche Popolari dell'Emilia Romagna Marche, 1997, pp. 15-17.

22 ROSSINI, Orietta, Ara Pacis, Milán, Electa, 2006, esp. pp. 80-93.

23 Acerca de la decoración fitomorfa en esta época puede consultarse: GHISELLINI, Elena, "Modelli ufficiali della prima età imperiale in ambiente privato e municipale", Mitteilungen des Deutschen Archäologischen Instituts - Römische Abteilung / Bullettino dell'Istituto Archeologico Germanico, Sezione Romana, 95 (1988), pp. 187-204 y tav. 70 a 75; SAURON, Gilles, L'histoire végétalisée. Ornement et politique à Rome, París, Antiqua e Picard, 2000; y CANEVA, Giulia, Il 

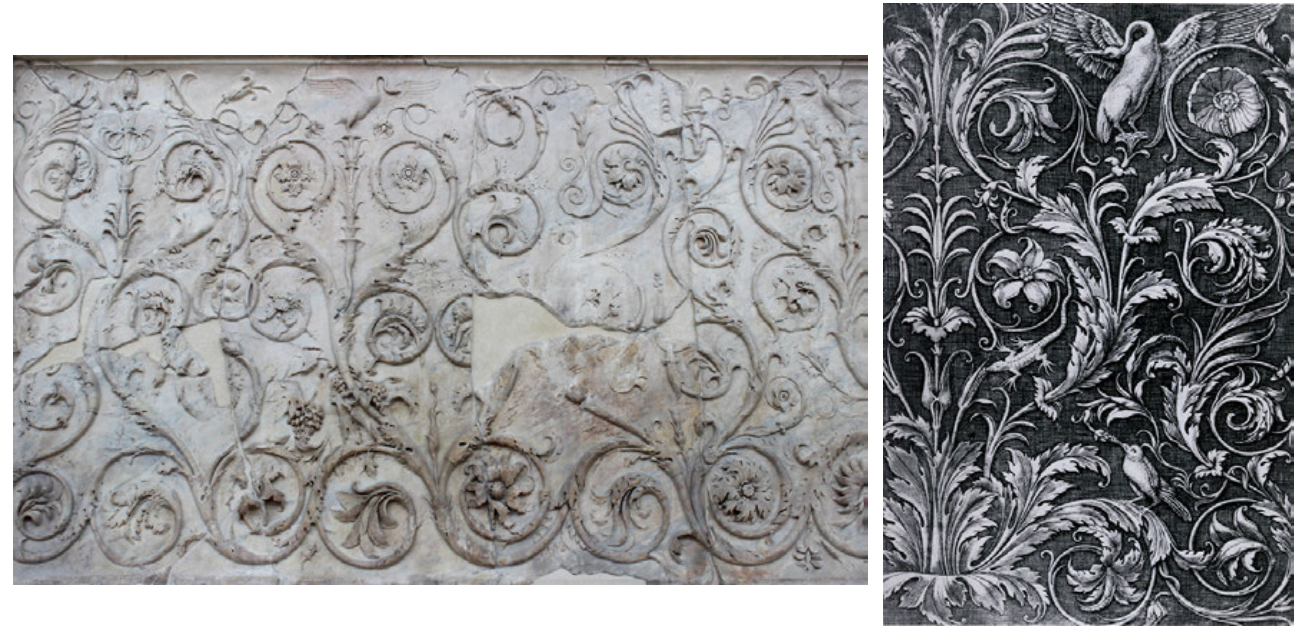

Fig. 11. Relieve de roleos vegetales y animales. Detalle del lado sur. Ara Pacis Augustæ de Roma. 13 y 9 a. C. Foto Rebeca Carretero

Fig. 12. Grabado de un fragmento de la decoración del Ara Pacis. Agostino Musi. 1536

espacio central para otros elementos como jarrones de flores -como sucede en el frontal del retablo mayor de la colegiata de Borja- o representaciones figuradas, y actúa como distribuidor del resto de flores. A esto hay que añadir que los autores de los relieves romanos incluyeron entre los roleos insectos, anfibios y pájaros de especies propias de la ribera del Tíber, concediendo una visión realista al exorno del altar, igual que hicieron los scagliolisti en sus obras. En este sentido, resulta interesante advertir que el monumento romano estaba en origen totalmente policromado ${ }^{24}$.

Los primeros restos del monumento augustano se descubrieron antes de 1536, fecha de la publicación de un grabado de Agostino Musi -conocido como Agostino Veneziano- que reproduce un fragmento del Ara Pacis con roleos ahora perdido (Fig. 12). En 1566 se exhumaron varias piezas más en el emplazamiento original del altar, en un lateral de la antigua vía Flaminia -en la actualidad del Corso- que fueron a parar a diferentes colecciones o enclaves, como a la fachada que mira al jardín de la Villa Medicis de Roma.

No obstante, algunos pintores ya se habían servido de motivos similares en sus pinturas murales como fue el caso de Andrea Mantegna

codice botanico di Augusto: Roma, Ara Pacis. Parlare al popolo attraverso le immagini della natura, Roma, Gangemi Editore, 2010.

24 FORESTA, Simone, "La policromia dell'Ara Pacis e i colori del Campo Marzio settentrionale", en ROSSI, Maurizio (a cura di), Colore e Colimetria. Contributi Multidisciplinari, vol. VII A, Atti della Settima Conferenza Nazionale del Colore, Rimini, Maggioli Editore, 2011, pp. 333-340. 


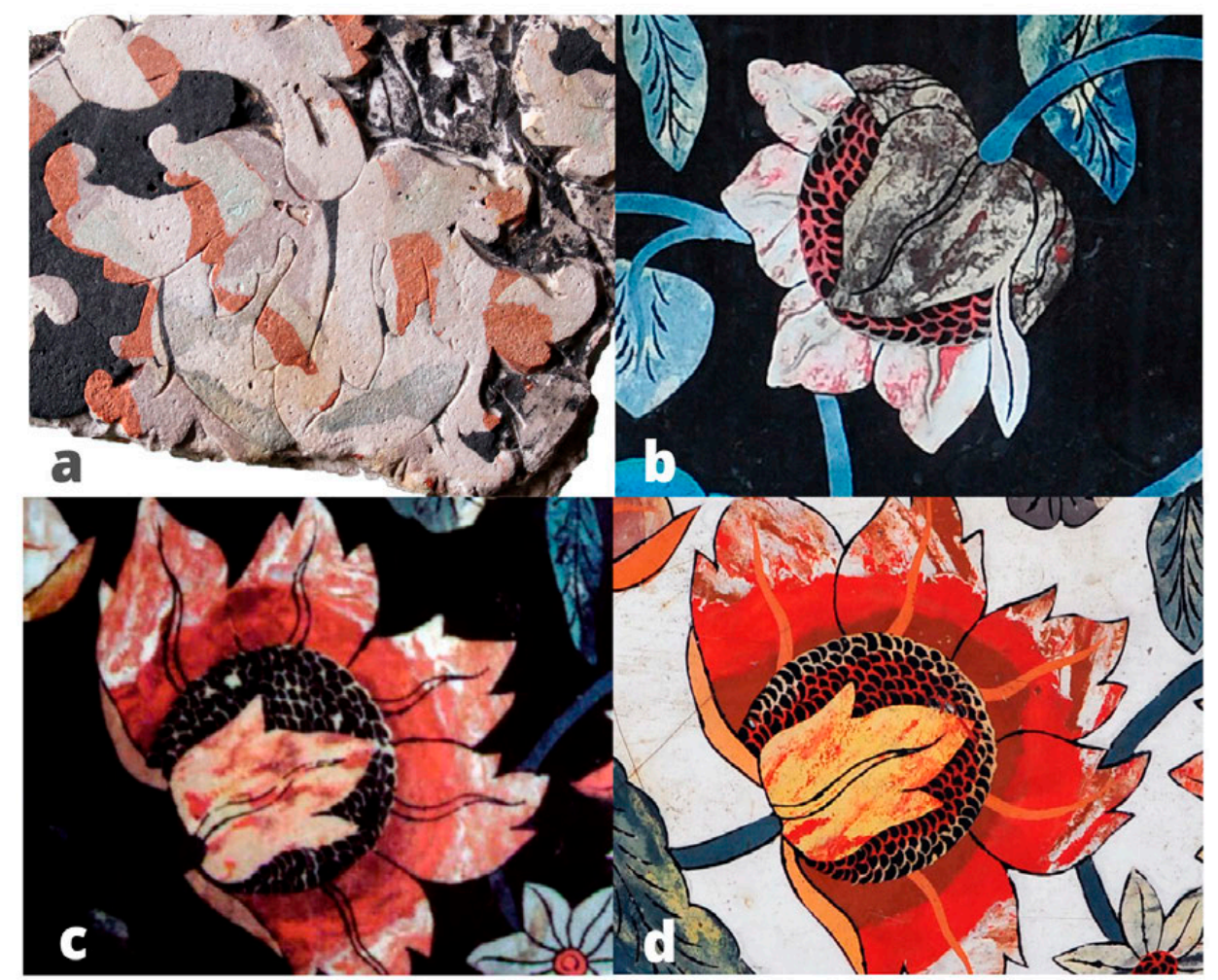

Fig. 13. Detalle de anémonas representadas en cuatro frontales de scagliola: a) fragmento de la iglesia de San Miguel de Borja; b) frontal de la colegiata de Santa María de Borja; c) frontal de la capilla de la Virgen del Rosario de la parroquial de Malón; y d) frontal de la capilla de San José de la iglesia del Seminario de San Carlos Borromeo de Zaragoza. Fotos Rebeca Carretero, Jesús

Criado, Centro de Estudios Borjanos y Jesús Criado, respectivamente

(h. 1431-1506), que ornó con roleos acantiformes las pilastras fingidas de la conocida como cámara de los esposos del Palazzo Ducale de Mantua, obra fechada entre 1465 y 1474. De igual manera, este tipo de exorno aparece empleado en mármoles del Renacimiento veneciano a partir del siglo $\mathrm{XV}^{25}$. De este modo, podemos establecer que estos motivos vegetales for-

25 Como ejemplo, baste citar el friso del entablamento de la portada principal de la iglesia de Santi Giovanni e Paolo, ejecutado a partir de 1458 bajo la responsabilidad de Bartolomeo Buon, o las lesenas y pilastras del coro de San Giobbe de Venecia, datado h. 1474. Véase WOLTERS, Wolfgang, Architettura e ornamento. La decorazione nel Rinascimento veneziano, Verona, 
maban parte del imaginario de los artistas del norte de Italia de los siglos XVI y XVII.

Aparte de acantos, en el fragmento que estudiamos creemos reconocer la representación de una de las flores que aparece con mayor frecuencia en los frontales de scagliola conservados en territorio aragonés. Se trata de la flor identificada como la anémona (Anemone coronaria) (Fig. 13 a) y que distinguimos en gran número en el paliotto del altar mayor de la colegiata de Santa María de Borja (Fig. 13 b) ${ }^{26}$, en el de la capilla de la Virgen del Rosario de la parroquial de Malón (Zaragoza) (Fig. 13 c), y en el del espacio litúrgico dedicado a San José que los duques de Villahermosa tenían en la iglesia del antiguo colegio de la Compañía de Jesús de Zaragoza, hoy Seminario de San Carlos Borromeo (Fig. 13 d), así como en el que realizó para la capilla de la familia Eguarás en la catedral de Santa María de la Huerta de Tarazona (Zaragoza), en la actualidad en paradero desconocido.

\section{3. Otra obra similar (y completa) en Borja: el frontal del altar mayor de la colegiata de Santa María}

Como avanzamos, la ciudad de Borja conserva una extraordinaria obra de scagliola en perfecto estado de conservación: el frontal del altar mayor de la colegiata de Santa María (Fig. 2). Además, esta pieza está firmada y fechada por el veneciano Ambrosio Mariesque en 1688 (Fig. 3). Mide $345 \mathrm{~cm}$ de ancho por $92^{\prime} 5 \mathrm{~cm}$ de alto ${ }^{27}$ y $7 \mathrm{~cm}$ de grosor. Sobre un fondo negro, un jarrón con flores flanqueado por dos mariposas y dos pájaros se sitúa en el centro de la composición actuando como eje de simetría del conjunto. A ambos lados, dos papagayos dispuestos bajo sendos acantos en torno a los que se distribuyen diferentes especies florales completan el exorno del conjunto. Todo ello está enmarcado, tanto en la zona superior como en los laterales, por una cenefa de flores diversas encadenadas ${ }^{28}$.

Pese a las reducidas dimensiones del fragmento de scagliola que estudiamos, no dudamos en relacionar su paternidad con el artista veneciano Am-

Cierre Edizione, 2007, pp. 33-37. Agradecemos al profesor Jesús Criado Mainar tanto el conocimiento de esta bibliografía, como sus consideraciones al respecto.

26 DELGADO, Javier, Jardín cerrado..., p. 88; y CARRETERO CALVO, Rebeca, "Ambrosius Mariesque...", pp. 245-246.

27 No obstante, se aprecia a simple vista que el frontal ha sido recortado o, en el mejor de los casos, embutido en el suelo del presbiterio, por lo que su altura original sería un poco mayor, probablemente próxima al metro. De igual modo se concluye en DELGADO, Javier, Jardín cerrado..., p. 81.

28 La identificación de las flores y su supuesto significado se encuentra en DELGADO, Javier, Jardín cerrado..., pp. 88-91; y CARRETERO CALVO, Rebeca, "Ambrosius Mariesque...", pp. 244-254. 
brosio Mariesque, documentado en tierras moncaínas y en Zaragoza capital al menos entre 1688 y $1709^{29}$. Asimismo, a la luz de los datos que manejamos en la actualidad, proponemos la posibilidad de que este vestigio perteneciera al frontal de altar del retablo mayor de la iglesia de San Miguel de Borja (Fig. 7), confeccionado, como se recordará, antes de 1692, fecha de su colocación en el presbiterio del templo.

Por todo ello, podemos concluir que hacia 1688 Mariesque llevaría a cabo dos paliotti en scagliola para la ciudad de Borja: el conservado en la colegiata y el desgraciadamente desaparecido de San Miguel del que sólo nos ha llegado este pequeño resto.

\section{LA TÉCNICA DE LA SCAGLIOLA: ORIGEN Y CARACTERÍSTICAS GENERALES}

La scagliola es una técnica de imitación de piedras duras y mármoles de colores gracias a la utilización de yeso endurecido -obtenido a partir de la calcinación, molienda e hidratación de la piedra de yeso o "aljez"- mezclado con cola y pigmentos naturales ${ }^{30}$. El uso de esta técnica para llevar a cabo representaciones figuradas nació en las regiones de Baviera y del Tirol, pero fue en Italia, en concreto en Emilia-Romaña, donde se desarrolló en una auténtica red de botteghe en las que se fijaron sus rasgos principales. En esta zona italiana, debido a la ausencia de mármoles y gracias a la riqueza de yeso, se consiguió elaborar un material más maleable que el mármol. El yeso posee menor dureza -se encuentra en el grado 2, bastante blando, de la escala de Mohs, mientras que el mármol está entre el 3 y el 4-, pero, salvando las distancias, presenta interesantes posibilidades de emular sus colores y brillo.

En general, la scagliola se empleó para decorar tableros de mesa, cuadros, paneles aplicados a muebles que ornamentarían los interiores de las viviendas nobiliarias y frontales de altar para las iglesias. En el norte de Europa esta técnica nació vinculada a la realeza, pero en la región italiana el comitente fue generalmente eclesiástico ${ }^{31}$.

En efecto, en Baviera y el Tirol la scagliola se comenzó a emplear en la corte del archiduque Fernando II de Austria (1578-1637). En Salzburgo, Hans Kerschpaumer confeccionó para él tableros de mesa en estuco coloreado decorados con diversos motivos como pájaros, paisajes, escudos de armas y jarrones. Poco después, fue Blasius Pfeiffer (act. 1587-1622) quien se sirvió de esta técnica para decorar el palacio residencial de Múnich. Una de sus principales obras es el revestimiento mural de la Reiche Kapelle de la residencia

29 Véase CARRETERO CALVO, Rebeca, “Ambrosius Mariesque...”, pp. 233 y 254-258.

30 Vertemos aquí parte de la explicación de la técnica expuesta en CARRETERO CALVO, Rebeca, "Ambrosius Mariesque...", pp. 238-244.

31 MANNI, Graziano, I Maestri..., p. 7. 
real de Múnich llevado a cabo con paneles de scagliola policroma imitando incrustaciones en mármol, que además incluye paneles con arquitecturas y escenas marianas ${ }^{32}$.

Aunque la historiografía asegura que el archiduque tenía en exclusiva esta técnica, casi coetáneamente, en la ciudad italiana de Carpi (Emilia-Romaña), el artista Guido Fassi -también conocido como Guido del Conte- parece que la empleó ya en 1611. No obstante, la evolución hacia la figuración se alcanzó aquí a partir de la década de 1640 de la mano de otros artífices, bastante más tarde que en las regiones germánicas. La razón que algunos autores consideran para explicar esta coincidencia es que, de algún modo, los carpigianos "espiaron" el trabajo de Pfeiffer en Múnich prediciendo el potencial de explotación comercial de esta nueva técnica ${ }^{33}$.

Desde Carpi, la scagliola se difundió gracias a la movilidad de los maestros que, una vez formados, se dispersaron por el área de Módena y de Reggio Emilia y después del resto de Italia a partir de la segunda mitad del siglo XVII y a lo largo de todo el XVIII ${ }^{34}$.

Gracias a la restauración de algunas de estas piezas podemos conocer cuáles eran los pasos seguidos en su elaboración, además de los materiales empleados. No obstante, es necesario advertir que las fases no eran exactamente iguales si la obra era monocroma -en blanco y negro, como lo fueron los primeros ejemplos carpigianos- o policroma. Así, en primer lugar, se realizaba una plancha de yeso, de entre 5 y $8 \mathrm{~cm}$ de grosor, en algunas ocasiones era armada con tallos de cáñamo o creada mediante un marco de madera que la rodeara, pero que después debía ser retirado. Si la pieza era monocroma, una vez seca la base se extendía una capa de yeso negro -compuesto de yeso, cola vegetal y color negro de humo- de pocos milímetros. Este estrato se pulía con piedra pómez y aceite de oliva, de lino o de nuez y se dejaba secar. A continuación, la superficie se grababa con buril delineando el diseño que estaba previamente preparado en un cartón disponiéndolo encima y agujereándolo. En los surcos creados se introducía scagliola blanca obteniéndose la base de la figura.

Si la pieza era policroma la base no debía ser recubierta con yeso negro y se trasladaba el diseño directamente sobre la superficie blanca. Se realizaban las incisiones pertinentes y se introducía en ellas la pasta de yeso del color deseado -generado previamente con la mezcla del pigmento correspondien-

32 Esta obra fue comenzada por Pfeiffer en 1607 y concluida por su hijo Wilhelm hacia 1630. Véase MANNI, Graziano, I Maestri..., pp. 14-15.

33 MANNI, Graziano, I Maestri..., pp. 15-17.

34 MANNI, Graziano, I Maestri..., pp. 20-29; y MANDER, Micalea, "Scagliole tra Emilia e Lombardia: una sintesi", en RÜSCH, Elfi (coord.), Scagliole intarsiate. Arte e tecnica nel territorio ticinese tra XVII e XVIII secolo, Milán, Silvana Editoriale, 2007, pp. 20-23. 

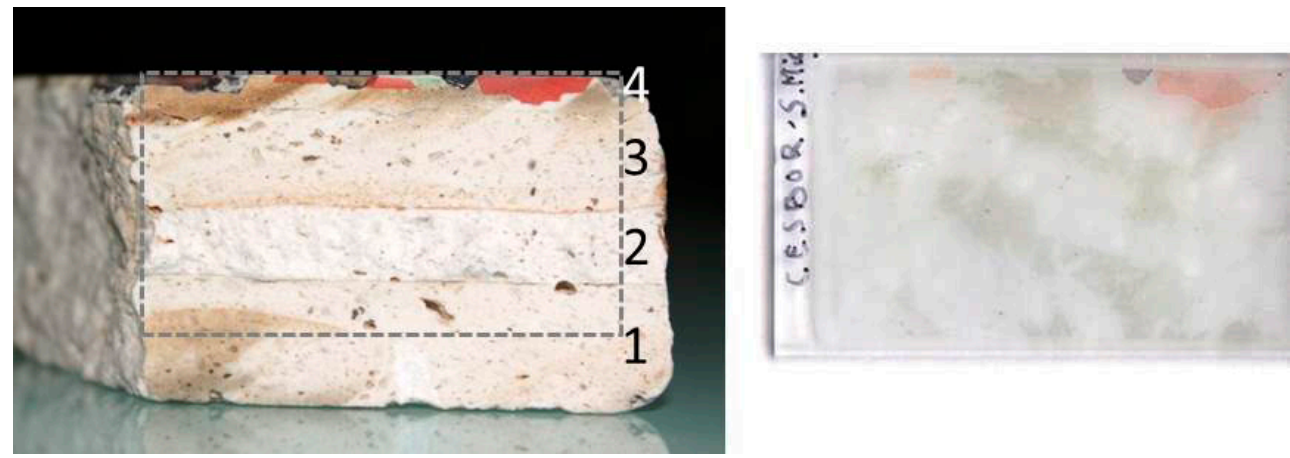

Fig. 14. Izquierda: Corte realizado en el fragmento de scagliola procedente de la iglesia de San Miguel de Borja, con indicación numérica de la superposición de capas. Foto Rebeca Carretero. Derecha: Imagen de la lámina delgada elaborada a partir del corte del fragmento. Foto Pilar Lapuente

te con la scagliola blanca-. A continuación, se pulía con aceite vegetal y piedra pómez. Según la complejidad del diseño, las labores de excavado, llenado y pulido podían volver a realizarse.

Por último, cuando el trabajo estaba completamente seco, se aplicaba aceite de nuez con la finalidad de otorgarle una impermeabilización profunda, así como de resaltar los colores ${ }^{35}$. Después, se trataba la superficie con cera de abejas para conseguir un aspecto de tanto brillo como el del mármol pulido. A pesar de esta apariencia marmórea, su manufactura es frágil y vulnerable a la humedad pues el yeso, base de esta técnica, es un material higroscópico ${ }^{36}$.

Pese a que este es el procedimiento que en general era seguido para su realización, el estudio del vestigio del frontal de la iglesia de San Miguel de Borja (Fig. 1), ha revelado la manera de trabajar de su artífice que identificamos con el veneciano Ambrosio Mariesque. Así, podemos asegurar que el scagliolista italiano afincado en Aragón creó una plancha de yeso de 3,7 cm de grosor sin reforzar con cáñamo. Una vez seca, grabó el diseño previsto con un elemento punzante y plano cuyas marcas se aprecian perfectamente en la superficie del fragmento. A demanda del diseño, en los surcos creados

35 En realidad, su elaboración es mucho más compleja y lenta debido a los tiempos de secado que necesita cada una de las fases de preparación de la base. Para una completa explicación de los pasos a seguir en la creación de la scagliola blanca y negra, tomando como base el manuscrito de 1684 atribuido al maestro de Carpi Giovanni Pozzuoli, véase DELLAPIANA, Laura, "La riscoperta di un paliotto in scagliola del 1681", Alba Pompeia, XXXIV, Fasc. II, Alba (2013), pp. 73-84, esp. pp. 74-75. La transcripción íntegra del manuscrito de 1684 se encuentra en MASSINELLI, Anna Maria, Scagliola. L'Arte della pietra di luna, Roma, Editalia, 1997, pp. 242-249.

36 MANNI, Graziano, I Maestri..., pp. 29-31; y MASSINELLI, Anna Maria, Scagliola. L'Arte..., pp. 193-215. 


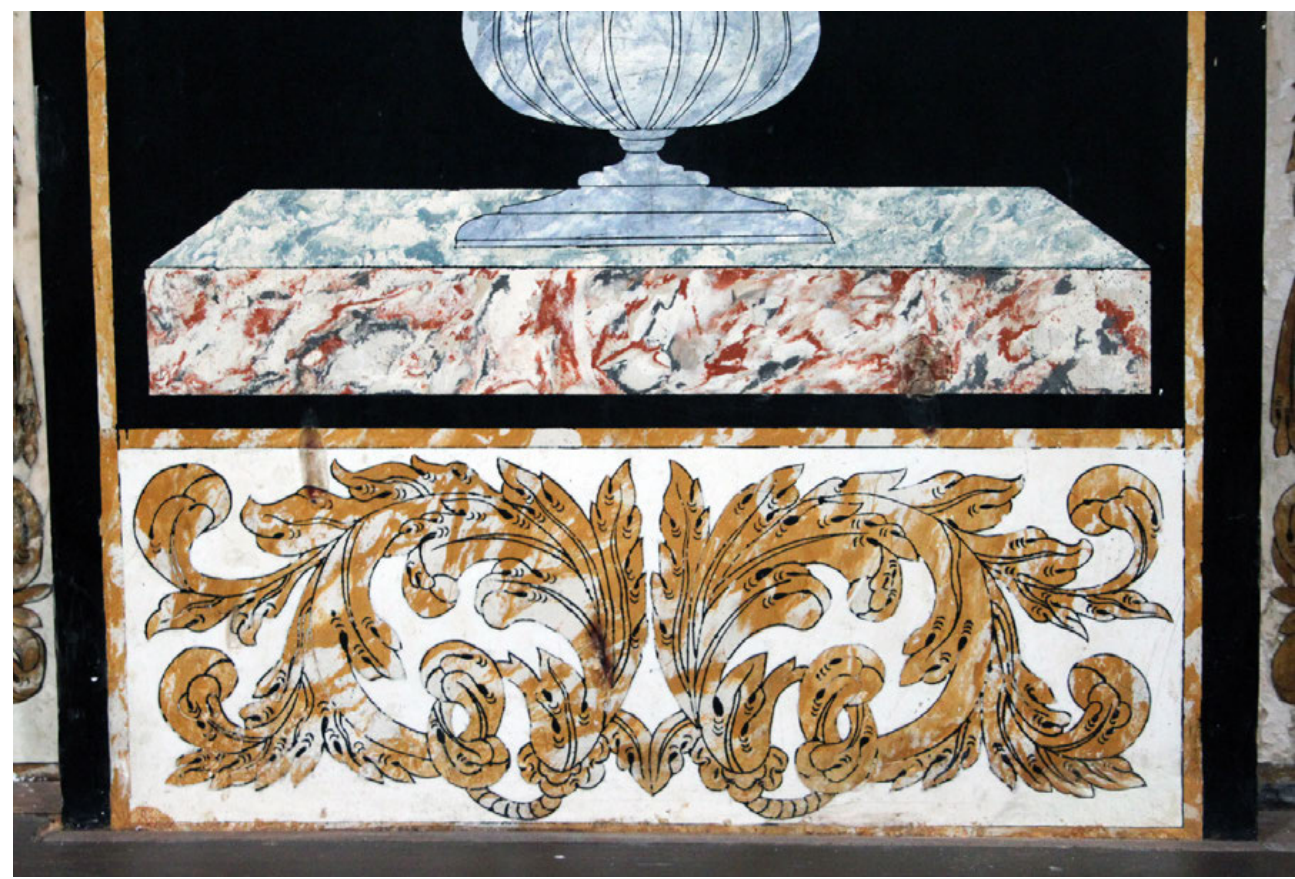

Fig. 15. Detalle de uno de los paneles de scagliola con la representación de un jarrón con flores. Capilla de San Andrés de la catedral de Santa María de la Huerta de Tarazona. Foto Rebeca Carretero

introdujo scagliola de colores. Lamentablemente, debido al paso del tiempo y por haber perdido la capa de protección final, los colores se han oxidado sobremanera alterando su aspecto y viveza originales.

Sin embargo, tenemos más información gracias al corte realizado en uno de los laterales menores en el año 2002 (Fig. 14, izquierda). Así, podemos observar que los colores empleados fueron el verde -muy inestable pues se ha aclarado hasta casi desaparecer-, el anaranjado -que parece que ha permanecido prácticamente invariable- y el rojo -que ha virado completamente a gris-.

Además, también podemos asegurar que Mariesque utilizó dos técnicas decorativas distintas en su elaboración: por un lado, rellenó los huecos creados en la scagliola, pero, por otro, pintó directamente algunas partes de la superficie con pintura ${ }^{37}$, detalle que se aprecia claramente en el uso del verde y en algunas partes del rojo, como se describirá más adelante. Esta circunstancia podría deberse a cuestiones de tipo económico, o quizá a razones pu-

37 Estas dos modalidades aparecen señaladas en GALLO COLONNI, Gabriella y BACCESCHI, Edi, "La incrustación", en MALTESE, Corrado (coord.), Las técnicas artísticas, Madrid, Cátedra, 1980, pp. 354-355; y en DELGADO, Javier, Jardín cerrado..., pp. 95-96. 
ramente artísticas ya que es posible que el tratamiento final tanto cromático como estético que quiso otorgar a la obra así lo demandara.

De hecho, examinando la única pieza firmada por Mariesque en Aragón -el ya mencionado frontal de la colegiata de Santa María de Borja- nos percatamos de que el jarrón con flores que la preside y algunos de los motivos representados exhiben exactamente esta misma gama de colores. De igual modo, este cromatismo aparece también en el zócalo de scagliola de la capilla de San Andrés de la catedral de Tarazona, obra atribuida al veneciano ${ }^{38}$, tanto en algunos de los paneles de decoración geométrica, como en el frente del neto en el que se apoya el jarrón con flores que lo orna (Fig. 15), además de en los roleos, los cueros recortados del escudo y varias de las flores del paliotto de la capilla de San Pedro Nolasco de la Seo de Zaragoza, también adjudicado a Mariesque ${ }^{39}$.

\section{ESTUdio PETROLÓgICO DEL FRAGMENTO DE SCAGLIOLA}

\section{1. Metodología}

Con objeto de conocer aspectos relacionados con la preparación y ejecución de la scagliola, y tal y como se ha mencionado previamente, el fragmento se seccionó transversalmente por el lateral de menor dimensión obteniendo un corte estratigráfico limpio de 3,7 cm de espesor. En el corte se evidencia la presencia de cuatro capas de estuco diferentes en color, textura y espesor (Fig. 14, izquierda), numeradas de 1 a 4 en el orden de la secuencia de ejecución. Estas capas se describirán visualmente con la ayuda de una lupa binocular en el siguiente apartado. A su vez, esta superficie de corte facilitó la realización ${ }^{40}$ de una lámina delgada (Fig. 14, derecha), para su observación microscópica mediante dos técnicas complementarias: la petrografía microscópica de luz transmitida ${ }^{41}$ y la microscopía electrónica de barrido con microanálisis por espectroscopía de rayos X. Con la primera se trata de identificar los componentes inorgánicos de la pasta empleada para realizar la scagliola y con la

38 CARRETERO CALVO, Rebeca, “La reforma barroca de la capilla de San Andrés de la catedral de Santa María de la Huerta de Tarazona", Toriaso, XXI (2012-2013), pp. 155-182.

39 Sobre esta pieza véase DELGADO, Javier, Jardín cerrado..., pp. 106-108.

40 La lámina delgada fue realizada por el personal del Servicio de Preparación de Rocas y Materiales duros perteneciente a los Servicios Generales de Apoyo a la Investigación de la Universidad de Zaragoza, a quienes se agradece el trabajo llevado a cabo.

41 El microscopio usado es un Carls Zeiss del Laboratorio de Microscopía del área de Petrología y Geoquímica de la Universidad de Zaragoza. A este instrumento se le acopla una cámara fotográfica para la obtención de microfotografías en condiciones de luz polarizada plana (nícoles paralelos) y cruzada analizada (nícoles cruzados). 
segunda, los pigmentos minerales. Se sabe que determinados aditivos, generalmente de origen animal, retrasan el fraguado, aumentan la plasticidad y trabajabilidad de estas pastas en estado fresco y mejoran la adherencia, dureza y resistencia a agentes externos. A este respecto, es preciso hacer notar que los posibles componentes de tipo orgánico como grasas, resinas o colas no se pueden detectar con ninguna de las dos técnicas utilizadas.

La microscopía óptica de luz transmitida es la técnica habitual del estudio petrológico que, con la ayuda del denominado microscopio petrográfi$\mathrm{co}$, permite visualizar la textura de sus componentes minerales así como su identificación a partir de su comportamiento óptico. La muestra obtenida en el corte del fragmento se reduce por abrasión hasta rebajarla a un espesor de 30 micras, para que pueda ser observable, una vez pegada a presión sobre un cristal portaobjetos, con la ayuda del microscopio. Este instrumento lleva incorporada una cámara fotográfica para obtener imágenes en distintas condiciones de luz polarizada. Los objetivos utilizados, de aumentos variables entre x3,5 y x50, facilitan una escala de observación suficiente para caracterizar la composición del soporte, habitualmente yeso puro o en mezcla con componentes carbonatados, ya sea cal o polvo de mármol. Igualmente, observando la muestra en distintas condiciones de luz polarizada, se reconocen con facilidad las diferentes capas, su textura y la unión entre ellas. Sin embargo, la escala de trabajo no es suficiente para identificar los granos correspondientes a los pigmentos utilizados.

La misma lámina delgada (Fig. 14, derecha), una vez metalizada con carbono, fue observada y analizada mediante la técnica de microscopía electrónica de barrido $(\mathrm{MEB})^{42}$. Se usó un voltaje de aceleración de $20 \mathrm{kV}$, se realizaron microanálisis elementales y se tomaron imágenes en modo BSE (Backscattered electron) o electrones retrodispersados. Los electrones BSE se producen por efecto de "rebote" sobre los átomos de la muestra. Cuanto mayor es la densidad del átomo (mayor masa atómica), mayor es la intensidad de electrones rebotados. La imagen que se produce responde a las distintas intensidades detectadas, por lo que pueden distinguirse zonas con distinta composición química. Estas imágenes facilitan la localización de heterogeneidades en la composición y en especial la presencia de las partículas de granulometría muy fina que constituyen los pigmentos.

Al realizar el estudio con microanálisis por rayos $X$ acoplado al MEB se detecta la composición cualitativa elemental de la muestra. Es necesario advertir que la sensibilidad del equipo no permite detectar elementos de número atómico bajo, como son el carbono (C) y el oxígeno (O). Por ello, cuan-

42 Se utilizó un equipo JEOL JSM 6400 con sistema de microanálisis elemental por espectroscopía de rayos X (eXL-10) LINK ANALYTICAL, del Servicio de Microscopía Electrónica de los Servicios de Ayuda a la Investigación (SAI) de la Universidad de Zaragoza. 
do se pretende conocer qué fases minerales se están analizando, no siempre será posible concretar el tipo de compuesto, indeterminación que afecta a carbonatos y a óxidos. En las imágenes tomadas se indican los elementos detectados mediante este microanálisis.

\section{2. Descripción macroscópica de la scagliola}

Según se ha dicho anteriormente, en el corte realizado son visibles 4 capas, con un total de $37 \mathrm{~mm}$ de espesor total de estuco de yeso, identificado por su baja dureza como resistencia al rayado, composición que se verifica microscópicamente en el siguiente apartado. Las tres primeras capas (1), (2) y (3) tienen una textura granulosa, muestran porosidad y sirven de soporte a la taracea decorada que constituye la última capa (4). En las capas (1) y (3) se observan algunos componentes subangulosos a subredondeados dispersos por el conjunto y algunos macroporos que superan los $2 \mathrm{~mm}$ de diámetro máximo. Esta característica debe relacionarse con la manipulación de la pasta de yeso hidratada que con objeto de homogeneizarla debió de batirse con intensidad provocando la entrada de burbujas de aire en su interior. La capa central del soporte (2), con un espesor en torno a $8 \mathrm{~mm}$ es bastante más uniforme, de granulometría muy fina y mucho más blanca que las otras dos del soporte. Presenta la misma apariencia macroscópica que la última capa (4) en la parte que no está decorada. Los límites de separación entre unas y otras capas son rectilíneos y entre la capa central (2) y la última del soporte (3) se observa una fina coloración de oxidación que pone de manifiesto que entre la aplicación de una y otra capa se permitió el tiempo suficiente para su secado y oxidación en contacto con el aire atmosférico (Fig. 14, izquierda). Esta circunstancia y el hecho de que ambas partes (2) y (4) sean similares podría deberse a la intencionalidad del artista de aumentar el espesor total del soporte antes de comenzar su decoración. Así, el grosor inicial de $22 \mathrm{~mm}$ que suponen en conjunto las capas (1) y (2), pasaría después casi a duplicarse, ya que los $37 \mathrm{~mm}$ que muestra ahora serían algo más antes de ser pulida su superficie en el proceso final.

En efecto, la última capa (4), en la que se aplicó la decoración, es irregular en cuanto a su espesor, con un máximo de $5 \mathrm{~mm}$; y mientras su límite interno es irregular, festoneado o con tramos rectilíneos, la superficie externa es completamente plana y rectilínea, sin duda obtenida por el pulido final. Su textura es muy fina, mucho menos granulosa que las capas internas, y con una marcada microporosidad. En cuanto a su coloración, visible en las partes que han quedado sin decorar, se observa un blanco luminoso similar al de la capa central (2) del soporte, de ahí que interpretemos que inicialmente el artista había pensado decorar esta capa (2) pero finalmente 
consideró que el soporte debería tener un mayor espesor, quizá influido por el tamaño total del frontal.

Observando en detalle esta capa externa (4), del corte estratigráfico con una lupa binocular, se identifican las improntas dejadas por los dos modos de proceder para disponer las partes coloreadas, característica que sin duda se observa mucho mejor a escala microscópica. Así, por una parte se observan los entrantes y salientes rectilíneos efectuados por incisión de una herramienta fina, posiblemente una espátula, para delimitar y generar los huecos en la scagliola. Estas incisiones llegan a profundizar entre 2 y $3 \mathrm{~mm}$ en la capa externa (4). Se trata de pequeñas porciones en las que se dispuso la misma pasta blanca previamente coloreada de forma uniforme con los distintos pigmentos. Por otra parte, en las zonas que no hay incisiones, la superficie de esta capa blanca o bien se deja sin pintar (correspondiendo a las partes decoradas superficialmente en blanco), o son visibles algunos trazos coloreados de escaso espesor, menores de $1 \mathrm{~mm}$, que pintan la propia pasta de yeso, ya sea en verde, o en un rojo suave anaranjado.

\section{3. Descripción microscópica}

La observación de la lámina delgada realizada con el microscopio petrográfico ha permitido verificar que se trata de un estuco de yeso taraceado. ${ }^{43} \mathrm{Se}$ han analizado las diversas capas que constituyen el soporte, así como las porciones de decoración seccionadas en la lámina.

Las zonas internas (1), (2) y (3) del soporte están constituidas por una pasta de yeso blanco bastante puro, en la que los únicos agregados observados son también de yeso, gránulos de yeso alabastrino (lenticular y fibroso) muy limpio y de gran pureza que se observan en las capas (1) y (3) (Fig. 16). Estos componentes subredondeados a subangulosos se encuentran dispersos por la matriz y sus dimensiones varían entre 400 micras y varios milímetros. Presentan un contacto relativamente bien definido con la matriz microcristalina y constituyen agregados irregulares de cristales que muestran textura de reacción con la matriz que los envuelve. Así, es visible una agradación de tamaño desde el borde y una disposición subperpendicular de los cristales respecto al borde del agregado ${ }^{44}$. Como ya se ha comentado en el apartado anterior, ambas capas (1) y (3) presentan una abundante ma-

43 Es decir, tallado y rellenadas las partes con estuco a la manera de las marqueterías de piedra dura.

44 Se asocian con las morfologías definidas por algunos autores como áridos de yeso tipo 2, descritos en algunos morteros históricos, véase IGEA ROMERA, Jesús; LAPUENTE MERCADAL, Pilar y MANDADO COLLADO, Juan, “Aproximación al Estudio Petrográfico de Áridos Yesíferos en Morteros. Ejemplo de Sta. María de la Huerta, Magallón (Zaragoza)", Macla, 9 (2008), pp. 133-134. 


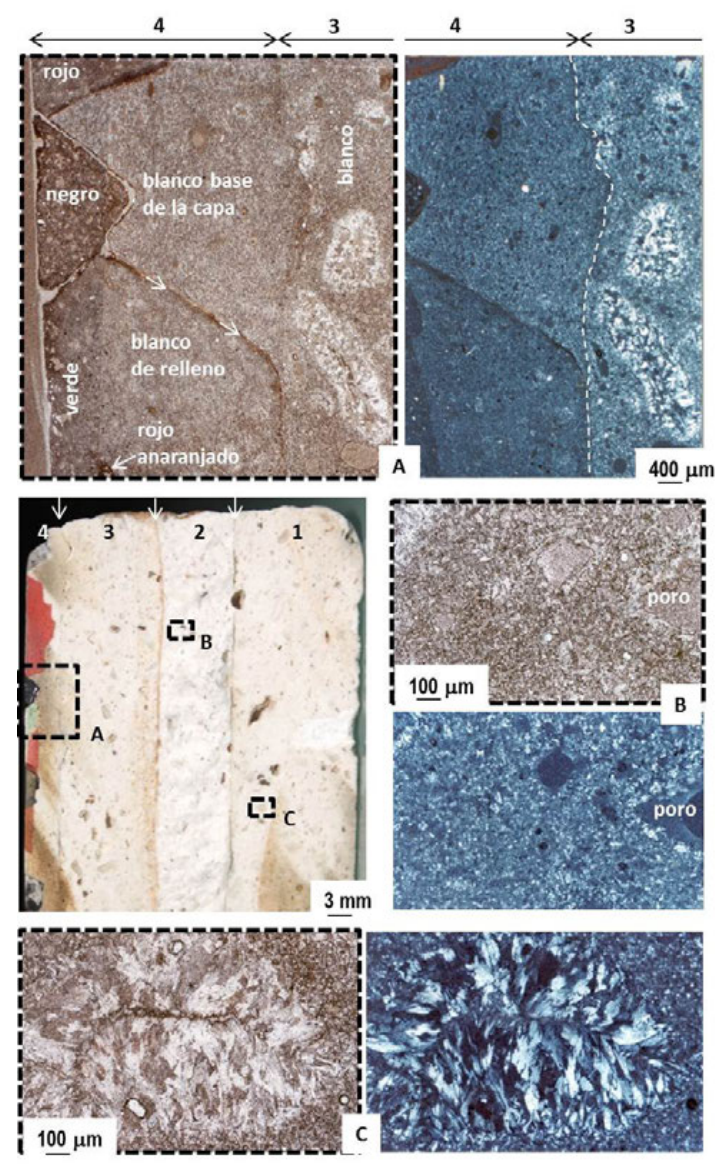

Fig. 16. Lámina de imágenes petrográficas en diferentes condiciones de luz observadas en las zonas (A), (B) $y(C)$ que se detallan en la sección del fragmento de scagliola estudiado que se muestra en la imagen central de la izquierda. Fotos Pilar Lapuente.

(A) Imágenes petrográficas de la parte externa de la scagliola, capa (4), con taracea en rojo y negro; el verde y el rojo que asoma por la parte inferior de la imagen se encuentran pintados sobre el blanco que rellenó la hendidura realizada sobre el blanco de la capa exterior (4). Se observa que no existen diferencias entre los dos blancos de la capa (4), pero sí con el estuco de la capa (3) que contiene gránulos de yeso alabastrino. Izda: NP; Dcha: NC.

(B) Imágenes petrográficas de un detalle de la capa central del soporte de la scagliola, capa (2). Arriba: NP; Abajo: NC. Matriz microgranulada de yeso alabastrino muy fino con polvo de cal, observada en NP. Su textura, microporosidad y composición coinciden con las de la capa blanca externa (4).

(C) Imágenes petrográficas de un detalle de un gránulo de yeso alabastrino de la capa interna del soporte de la scagliola, capa (1). Idéntico a los agregados que se observan en la capa (3). Nótese la textura de reacción en su borde con crecimiento de cristales de menor tamaño en su borde. Izda: NP; Dcha: NC. 

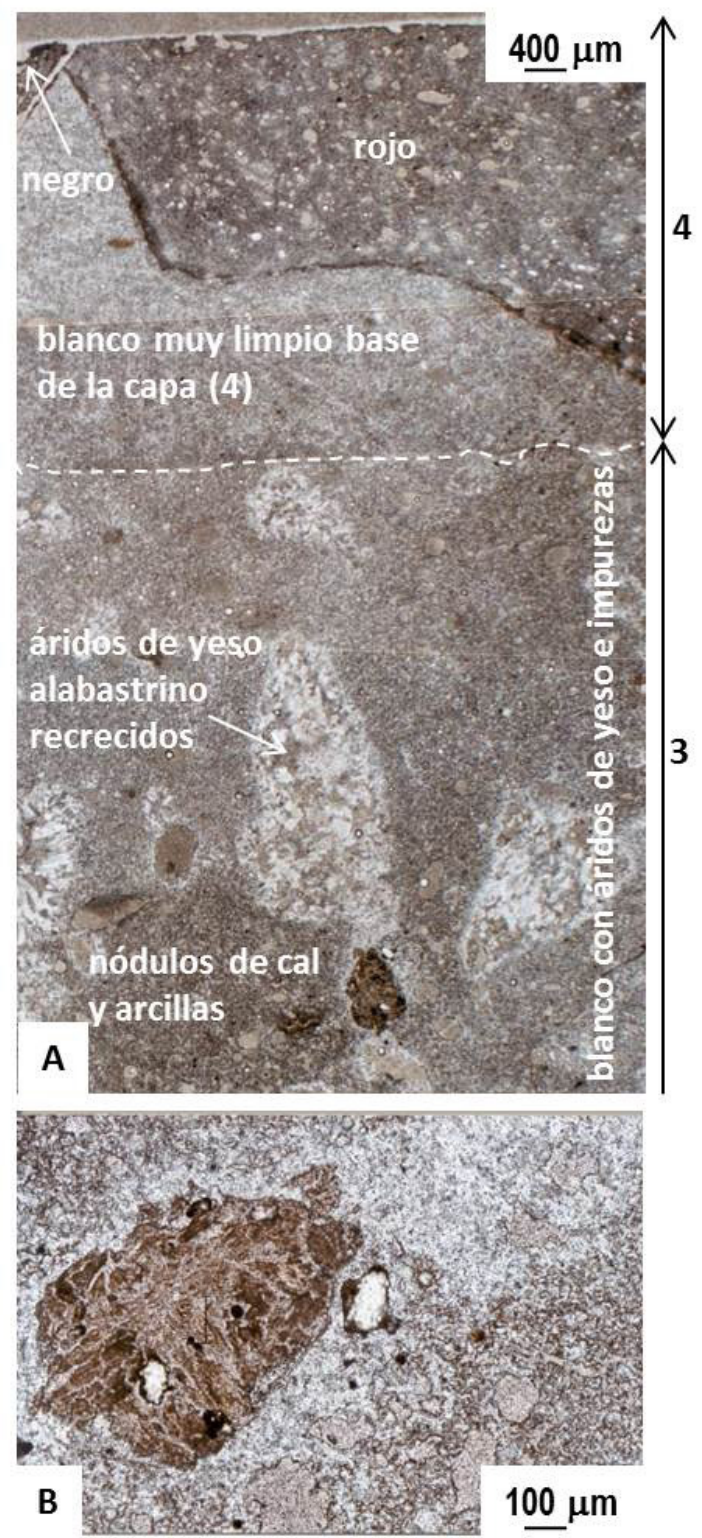

Fig. 17. Lámina de imágenes petrográficas en condiciones de luz polarizada plana $(N P)$. (A): sección del fragmento de scagliola del contacto entre las capas (4) y (3) orientado perpendicularmente a la imagen de la Figura 16. Se observa la heterogeneidad de la capa (3), con los áridos de yeso alabastrino que muestran textura de reacción con la matriz yesífera que los envuelve y nodulizaciones de cal con impurezas de arcillas. (B): Detalle de una estas impurezas. Fotos Pilar 
croporosidad y contienen algunos muy escasos nódulos de cal con impurezas de arcillas (Fig. 17).

Por su parte, las capas (2) y (4) presentan entre sí idéntica composición y textura, una pasta muy homogénea constituida por una matriz microgranulada de yeso alabastrino muy puro y fino mezclado con partículas de polvo de cal sumamente finas. Ambos componentes están íntimamente mezclados y proporcionan una microporosidad uniforme. Los beneficios de la adición de componentes de cal al yeso son bien conocidos en morteros históricos, ya que mejoran la trabajabilidad de la pasta retardando el fraguado del yeso e incrementando su resistencia ${ }^{45}$.

En la figura 16 se ilustra con imágenes petrográficas a distinta microescala las características observadas en las distintas capas de la scagliola. En la imagen (A) se aprecian los detalles de la parte externa (4) del estuco de yeso fino blanco muy puro en su contacto con el soporte (3) que contiene gránulos de yeso alabastrino. En especial en la imagen de la izquierda, realizada en condiciones de luz polarizada plana (NP), se observan diversos aspectos interesantes para conocer el modo de proceder del artista. Así son visibles las incisiones realizadas en la capa (4) para realizar la taracea, límites que se acentúan por la película de oxidación que bordea cada una de las porciones de la decoración, evidenciando un lapso de tiempo, entre la realización del festoneado y su relleno, suficiente para facilitar el proceso de reacción con el oxígeno atmosférico. No se descarta tampoco que una vez realizadas las incisiones, se impregnara la superficie con algún producto orgánico, o que incluso el estuco de yeso contuviese algún producto, posiblemente cola, que aumentara el efecto oxidante de su superficie. A este respecto, cabe recordar que también el límite externo de la capa (2) presenta esta misma película de oxidación, característica que reafirma la hipótesis propuesta de haber reforzado el soporte duplicando las capas.

Igualmente es evidente que eligió la misma pasta de yeso fino blanco muy puro para realizar la decoración, unas veces colorido, es decir teñido en su masa con tintes naturales de pigmentos minerales (como se describirá en el siguiente apartado, para el relleno de las taraceas en rojo y en negro), y otras veces teñido en su superficie y aplicado con brocha (caso del verde y del rojo anaranjado). Un último aspecto a destacar de esta imagen (A) es que el artista, al menos en la parte estudiada, rectificó el relleno de alguno de los huecos pensado inicialmente para una taracea colorida en toda su masa,

45 IGEA ROMERA, Jesús; LAPUENTE MERCADAL, Pilar; MARTÍNEZ-RAMÍREZ, Sagrario y BLANCO-VARELA, Ma Teresa, "Caracterización de morteros mudéjares de la iglesia de San Gil Abad (Zaragoza, España): Investigación de la tecnología de fabricación de morteros históricos de yeso", Materiales de construcción, vol. 62, nº 308 (2012), pp. 515-529 [consulta: 21 de marzo de 2020], disponible: https://doi.org/10.3989/mc.2012.07311 
y acabó introduciendo la misma pasta blanca para pintarla con brocha en su superficie exterior (en la imagen, el límite inferior rectilíneo del verde es muy sutil (con una traza pintada en torno a $0,8 \mathrm{~mm}$, a diferencia de los límites bien marcados de los bordes de la taracea). No cabe duda de que, de este modo, se economizaría el consumo de pigmentos.

Por último, en otras zonas del corte estudiado de la scagliola se observa que esta misma pasta, expuesta en su superficie, le sirve al artista para el blanco de la decoración del dibujo, confirmando la observación macroscópica ya expuesta en el apartado anterior. Igualmente, las imágenes petrográficas (B) y (C) de la figura 16, muestran detalles de las capas (2) y (1), respectivamente, que corroboran las descripciones macro y microscópicas realizadas.

En la figura 17, se complementa la imagen petrográfica anterior, orientada perpendicularmente a ella y con una mayor extensión que facilita la observación del aspecto que presenta la capa (3) del soporte. En ella son evidentes las formas irregulares de los áridos de yeso alabastrino y su recrecimiento por reacción de sus bordes en contacto con la matriz también yesífera. Igualmente, es visible la heterogeneidad de esta capa con la presencia de nodulizaciones de grumos de cal con impurezas de arcillas.

\section{4. Descripción de los pigmentos}

La coloración de los yesos es, como todas las técnicas relacionadas con este material, de gran complejidad. En cada color aplicado intervienen el pigmento, el disolvente y otros elementos auxiliares. Es preciso reseñar que no debe confundirse pigmento con colorante, ya que el uso de colorantes se generalizó a partir de las anilinas descubiertas en el siglo XIX. Según recoge Gárate Rojas ${ }^{46}$, los artesanos coinciden en que los colores orgánicos no soportan los yesos fuertes, por lo que generalmente se emplearon los inorgánicos como las tierras u óxidos minerales, bien en su estado natural, o manipulados por oxidación o calcinación, $\mathrm{u}$ obtenidos tras la precipitación de partículas en un medio adecuado, filtrándose tras su decantación. En cualquier caso, los pigmentos requieren una molienda extrema con un grado de finura extremo para su mejor rendimiento. Algunos son solubles en agua y otros en disolventes como alcohol, vinagre, etc., componentes imposibles de dilucidar con las técnicas aplicadas.

Cuando el yeso está pigmentado, coloreado en toda su masa, se dice que está colorido y en este caso el tratamiento se realiza durante el amasado del yeso para que las partículas del pigmento se distribuyan por todo el volu-

46 GÁRATE ROJAS, Ignacio, Artes de los yesos. Yeserías y estucos, Madrid, Ed. Munilla-Lería, 1999, p. 381. 
men. Se puede colorir de dos formas, o mezclando el yeso en polvo con una dosis precisa del pigmento, mezclando repetidamente y añadiendo después el agua necesaria para la hidratación, o bien se procede a desleír los pigmentos en poca cantidad de agua y con el agua coloreada se empasta el yeso. En este último caso, al teñirse el yeso en el secado se obtiene una coloración pálida y débil por lo que para obtener colores estables era habitual añadir alguna sustancia orgánica para regular la intensidad y distribución del color. Por otra parte, en la técnica de decorar el yeso ya fraguado pintándolo superficialmente se requiere que los microporos estén abiertos de forma natural para que penetre la pintura, por lo que no puede haberse alisado o pulido previamente.

Respecto a los pigmentos utilizados para los distintos colores, se sabe que para realizar las scagliolas se utilizaron algunos extremadamente caros, como son los verdes y amarillos, o determinados rojos, como es el bermellón o cinabrio, ya que el espectro de posibilidades dentro del mundo mineral es muy amplio y pueden obtenerse los mismos colores con diferentes productos.

Para alcanzar una visión aproximada de los pigmentos usados por el artista veneciano, se analizaron las porciones coloridas y pintadas que contiene la parte decorada de la lámina delgada, es decir, aproximadamente una porción de unos $13 \mathrm{~mm} \times 4,5 \mathrm{~mm}$. En la figura 18 se recogen imágenes de MEB en modo BSE (electrones retrodispersados) de la zona externa del corte realizado en la scagliola, prácticamente en la misma zona que la observada en la composición petrográfica de la figura 16. También aquí es de destacar que los bordes incisivos entre las distintas partes de la taracea presentan límites netos muy marcados y rectilíneos que ponen de manifiesto la utilización de una herramienta cortante de gran precisión ya que el espesor de las zonas decoradas es milimétrico.

En la imagen (A), se observa de arriba abajo, las decoraciones de las taraceas en rojo y en negro, ambas en porciones bien delimitadas, y en la parte inferior de las decoradas en verde y en rojo anaranjado. Obsérvese que la textura del estuco de yeso en toda la decoración, capa (4), es idéntica con la excepción de los pigmentos utilizados para cada color. Así, en la taracea roja se observa un punteado blanquecino que corresponde con el pigmento en polvo. Este pigmento se encuentra disperso de forma uniforme por todo el fragmento que compone esta taracea, confirmando que se trata de una porción de decoración colorida $a^{47}$ en toda su masa, con un espesor máximo de $3 \mathrm{~mm}$. Las imágenes (B) y (C) de esta figura 18 muestran en un mayor

47 Según la descripción realizada en el capítulo 4, Artes de colorir, de GÁRATE ROJAS, Ignacio, Artes de..., pp. 151-174. 


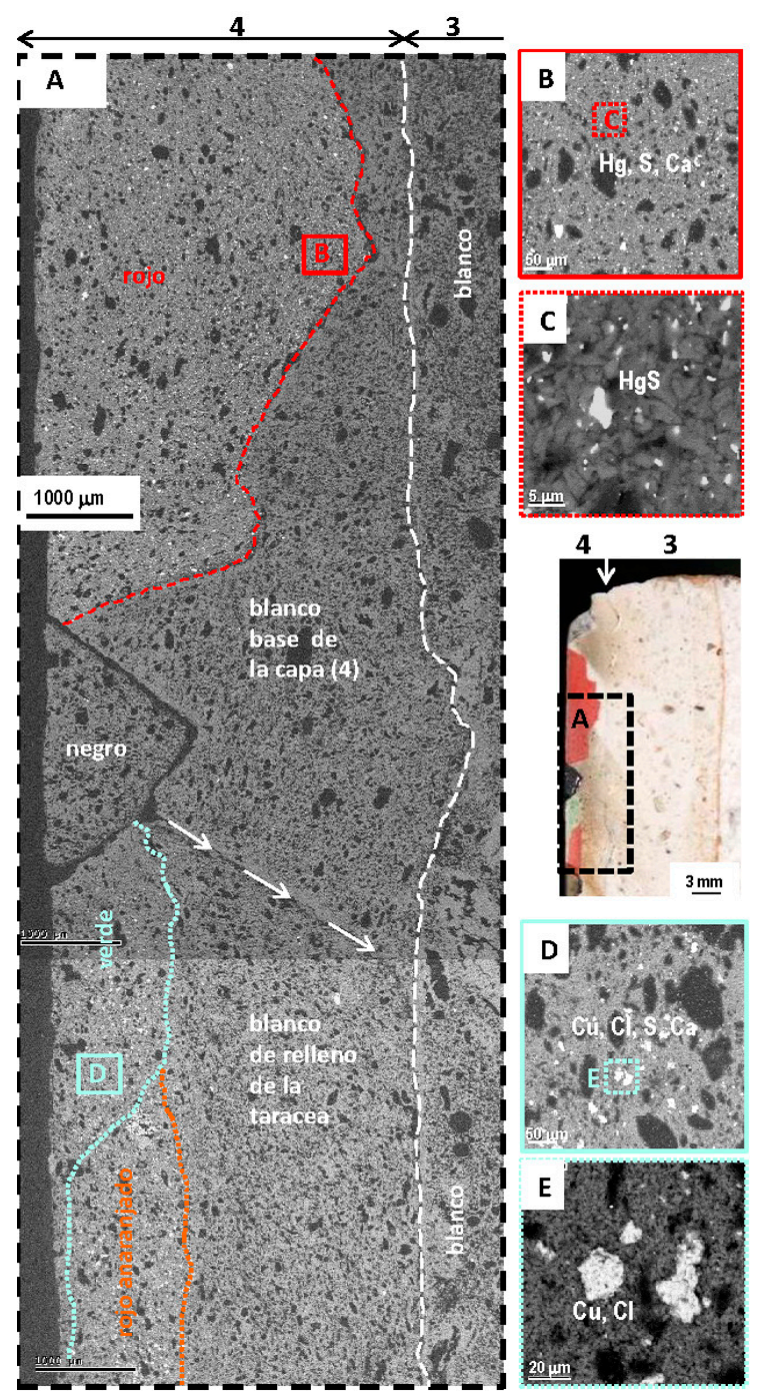

Fig. 18. Lámina de composición de imágenes $M E B$, en modo BSE, correspondientes a la zona externa de la scagliola, que se señala en recuadro $(A)$ de la imagen central de la derecha, del fragmento analizado en el contacto entre las capas (3) y (4). Fotos Pilar Lapuente.
(A) En la imagen se observan las diferencias texturales y las porciones de la taracea en rojo (arriba), en negro (centro) y la zona decorada en verde sobre una zona en rojo anaranjado; estas últimas pintadas sobre el relleno de una taracea en blanco (abajo). (Obsérvese la incisión, señalada con flechas blancas que la limita físicamente). La línea discontinua blanca marca la separación entre las capas (3) y (4).

(B) Sector analizado en la taracea roja, constituida por yeso (sulfato cálcico hidratado) pigmentado con microgránulos de cinabrio ( $\mathrm{HgS})$.

(C) Detalle de los granos de pigmento de cinabrio (gránulos blancos, en la imagen MEB).

(D) Detalle de la zona decorada en verde, correspondiente a la zona externa de la scagliola que se señala en el recuadro. La pincelada de aproximadamente $1 \mathrm{~mm}$ de espesor se realiza sobre el relleno de una porción de taracea en blanco.

(E) Sector analizado en la zona pintada de verde, constituida por yeso (sulfato cálcico hidratado) pigmentado con microgránulos de atacamita, $\mathrm{Cu} 2 \mathrm{Cl}(\mathrm{OH}) 3$, en blanco en la imagen MEB. 
detalle estos microgránulos blanquecinos. Su morfología es irregular y su tamaño variable entre menos de 1 micra y 30 micras de diámetro. En el microanálisis efectuado se detectó $\mathrm{S}$, Ca y $\mathrm{Hg}$, que ponen de manifiesto que se trata de yeso teñido con partículas de cinabrio, es decir, sulfuro de mercurio $(\mathrm{HgS})$, uno de los pigmentos más cotizados de la época. ${ }^{48}$ En el detalle de la imagen (C) se muestra la porción en la que se analizó una de estas partículas y la buena dispersión de los pigmentos en la matriz de yeso, aspecto que lleva a pensar en la meticulosidad de la ejecución del artista, que sugiere quizá en la utilización de algún medio disolvente orgánico adicional al agua en el amasado.

La taracea decorada en negro presenta una textura homogénea del yeso teñido en toda su masa. En el microanálisis se halló S, Ca y muy escasa proporción de $\mathrm{Sr}$, del que solo se detectaron cuatro escasos microgránulos en todo el fragmento. Estos podrían tratarse de impurezas de celestina (sulfato de estroncio) habituales en el propio yeso. En cualquier caso, estos componentes no pueden ser los responsables de su coloración negra debido a su escasa proporción y reducida distribución. De los posibles pigmentos -óxidos de hierro, carbón triturado, negro de grafito, negro de manganeso o el denominado negro de humo-, no puede tratarse de componentes de hierro ni de manganeso, ya que estos elementos habrían sido detectados fácilmente en el microanálisis, por tanto podría responder a cualquiera de los que es el carbono ${ }^{49}$ el responsable del color, bien fuese carbón triturado, negro grafito o humo negro ${ }^{50}$.

Respecto a la zona decorada en verde, tanto en la figura 16 como en la 18 se observa que responde a una coloración por pincelada superficial de aproximadamente $1 \mathrm{~mm}$ de espesor, o incluso menos, realizada sobre el relleno de una porción de taracea en estuco blanco, que incluso se superpone a otra pincelada de tonalidad rojo anaranjado. Es evidente que se trata de una decoración pintada y no taraceada o colorida en su totalidad, ya que en la imagen BSE de MEB (Fig. 18 (A)) no se reconoce ninguna incisión cortante o incrustaciones, sino que se observa una acumulación superficial de las minúsculas partículas blanquecinas, que corresponden con los pigmentos. Al aplicar el microanálisis a estas zonas pintadas se ha comprobado que los elementos $\mathrm{S}$ y Ca son los únicos componentes de las zonas blancas. Mientras que los corpúsculos responsables de la coloración verde corresponden con

48 Acerca de la obtención de este pigmento, sus tipos y características, véase BRUQUETAS GALÁN, Rocío, Técnicas y materiales de la pintura española en los Siglos de Oro, Madrid, Fundación de Apoyo a la Historia del Arte Hispánico, 2002, pp. 162-164.

49 Elemento que, por su bajo número atómico, no puede detectarse por esta técnica.

50 Sobre el negro de humo puede consultarse BRUQUETAS GALÁN, Rocío, Técnicas y materiales..., p. 172. 
cloruros de cobre, que pueden responder a atacamita, $\mathrm{Cu}_{2} \mathrm{Cl}(\mathrm{OH})_{3}$, según se muestra en las imágenes (D) y (E) de la figura 18.

Por último, respecto a la zona pintada de rojo anaranjado contiene los mismos elementos ( $\mathrm{S}, \mathrm{Ca}$ y $\mathrm{Hg}$ ) que la parte colorida en su totalidad de la taracea roja, de hecho parece corresponder con el mismo color más suave, de bermellón diluido.

\section{Conclusiones}

A partir del fragmento de scagliola estudiado y analizado con diversas técnicas, y a pesar de tratarse de una pequeña porción del malogrado frontal del altar de la iglesia de San Miguel de Borja, se ha podido extraer una valiosa información acerca del modo de proceder del artista veneciano en su ejecución.

Así, podemos asegurar que el soporte de la decoración lo realizó primero con dos capas de estuco de yeso, que posteriormente amplió a cuatro, hasta un total aproximado cercano a los $4 \mathrm{~cm}$. Estas capas, aun siendo mayoritariamente de yeso, muestran diferencias en cuanto a homogeneidad y pureza de componentes, así como de tonalidad en blanco. Igualmente, por una parte, el estuco del soporte, capas blancas (1) y (3) contienen áridos de yeso alabastrino en polvo relativamente fino y algunas nodulizaciones de cal con impurezas de arcillas, en una matriz microcristalina de yeso que reacciona con los bordes de los áridos. Se evidencia su porosidad a todas las escalas de observación. Mientras que la capa pensada para ser decorada -inicialmente la (2) y finalmente la (4)-, se trata de un estuco muy blanco y homogéneo composicionalmente, con marcada microporosidad, donde el yeso microcristalino se encuentra íntimamente mezclado con polvo de cal impalpable de gran finura. Es muy probable que este polvo muy fino estuviera diluido en una solución de cola, componente que, junto con la cal, podría haber reaccionado por oxidación en contacto con el aire atmosférico. Este supuesto parte de la observación de un límite de oxidación muy continuo tanto en el límite externo de la capa (2), como en los límites recortados y festoneados de la capa (4) que soporta la decoración, poniendo de manifiesto que, una vez preparado el diseño y recortadas las partes que iban a ser taraceadas, pasó un lapso de tiempo.

Cada pieza de la taracea presenta la misma composición y textura variando únicamente el pigmento utilizado para su coloración en masa. Se ha documentado que al menos se empleó cinabrio o bermellón, atacamita y seguramente negro de humo. Por último, es preciso recordar que el paso del tiempo y la oxidación de la superficie han modificado los colores o la intensidad de la coloración del fragmento de scagliola. 


\section{Bibliografía}

ARGAIZ, Gregorio de, Teatro monástico de la Santa Iglesia, ciudad y Obispado de Tarazo$n a$, t. VII de La Soledad Laureada por San Benito y sus hijos en las iglesias de España, Madrid, Antonio de Zafra, 1675.

Blog del Centro de Estudios Borjanos de la Institución "Fernando el Católico" [consulta: 06/01/2020], disponible: http://cesbor.blogspot.com/2018/11/una-piezaque-retorna-al-centro.html

BRESSEL ECHEVERRÍA, Carlos; LOMBA SERRANO, Concepción y MARCO FRAILE, Ricardo, Borja: arquitectura y evolución urbana, Zaragoza, Colegio Oficial de Arquitectos de Aragón, 1988.

BRUQUETAS GALÁN, Rocío, Técnicas y materiales de la pintura española en los Siglos de Oro, Madrid, Fundación de Apoyo a la Historia del Arte Hispánico, 2002.

CANEVA, Giulia, Il codice botanico di Augusto: Roma, Ara Pacis. Parlare al popolo attraverso le immagini della natura, Roma, Gangemi Editore, 2010.

CARRETERO CALVO, Rebeca, "La reforma barroca de la capilla de San Andrés de la catedral de Santa María de la Huerta de Tarazona", Tvriaso, XXI (2012-2013), pp. 155-182.

CARRETERO CALVO, Rebeca, “'Ambrosius Mariesque venetianus', un maestro de las piedras fingidas en Aragón", en LACARRA DUCAY, Mª del Carmen (coord.), Un olor a Italia. Conexiones e influencias italianas en el arte aragonés (siglos XIV-XVIII), Zaragoza, Institución "Fernando el Católico", 2019, pp. 229-259.

CRIADO MAINAR, Jesús y IBÁÑEZ FERNÁNDEZ, Javier, Sobre campo de azul y carmín. Programas de ornamentación arquitectónica al romano del primer Renacimiento aragonés, Zaragoza, Fundación Teresa de Jesús, 2006.

DELGADO, Javier, Jardín cerrado. Flora escondida en la colegiata de Santa María de Borja, Borja, Centro de Estudios Borjanos de la Institución "Fernando el Católico", 2001.

DELLAPIANA, Laura, "La riscoperta di un paliotto in scagliola del 1681", Alba Pompeia, XXXIV, Fasc. II, Alba (2013), pp. 73-84.

FORESTA, Simone, "La policromia dell'Ara Pacis e i colori del Campo Marzio settentrionale", en ROSSI, Maurizio (a cura di), Colore e Colimetria. Contributi Multidisciplinari, vol. VII A, Atti della Settima Conferenza Nazionale del Colore, Rimini, Maggioli Editore, 2011, pp. 333-340.

GALLO COLONNI, Gabriella y BACCESCHI, Edi, “La incrustación”, en MALTESE, Corrado (coord.), Las técnicas artísticas, Madrid, Cátedra, 1980, pp. 354-355.

GÁRATE ROJAS, Ignacio, Artes de los yesos. Yeserías y estucos, Madrid, Ed. Munilla-Lería, 1999.

GARCÍA, Rafael, Datos cronológicos para la historia de la M. N., M. L. y F. ciudad de Borja, Zaragoza, Tipografía del Hospicio Provincial, 1902.

GHISELLINI, Elena, "Modelli ufficiali della prima età imperiale in ambiente privato e municipale", Mitteilungen des Deutschen Archäologischen Instituts - Römische Abteilung / Bullettino dell'Istituto Archeologico Germanico, Sezione Romana, 95 (1988), pp. 187-204.

GRACIA RIVAS, Manuel, Guía para una visita a la Ciudad de Borja, Borja, Centro de Estudios Borjanos de la Institución "Fernando el Católico", 1987. 
GRACIA RIVAS, Manuel, El Museo de la Colegiata, Borja, Centro de Estudios Borjanos de la Institución "Fernando el Católico", 2003.

GRACIA RIVAS, Manuel, Diccionario biográfico de personas relacionadas con los veinticuatro municipios del antiguo Partido Judicial de Borja, Borja, Centro de Estudios Borjanos de la Institución "Fernando el Católico", vol. I, 2005.

IGEA ROMERA, Jesús; LAPUENTE MERCADAL, Pilar y MANDADO COLLADO, Juan, "Aproximación al Estudio Petrográfico de Áridos Yesíferos en Morteros. Ejemplo de Sta. María de la Huerta, Magallón (Zaragoza)", Macla, 9 (2008), pp. 133-134.

IGEA ROMERA, Jesús; LAPUENTE MERCADAL, Pilar; MARTÍNEZ-RAMÍREZ, Sagrario y BLANCO-VARELA, $M^{a}$ Teresa, "Caracterización de morteros mudéjares de la iglesia de San Gil Abad (Zaragoza, España): Investigación de la tecnología de fabricación de morteros históricos de yeso", Materiales de construcción, vol. 62, no 308 (2012), pp. 515-529 [consulta: 21 de marzo de 2020], disponible: https://doi.org/10.3989/mc.2012.07311

JIMÉNEZ APERTE, Manuel y ESCRIBANO SÁNCHEZ, José Carlos, “Iglesias medievales en la Comarca de Borja. I", Cuadernos de Estudios Borjanos, VII-VIII (1981), pp. 109-232.

JIMÉNEZ AZNAR, Emilio, El convento de Santa Clara de Borja (fundación y construcción), Borja, Centro de Estudios Borjanos de la Institución “Fernando el Católico", 2004.

MANDER, Micalea, "Scagliole tra Emilia e Lombardia: una sintesi", en RÜSCH, Elfi (coord.), Scagliole intarsiate. Arte e tecnica nel territorio ticinese tra XVII e XVIII secolo, Milán, Silvana Editoriale, 2007, pp. 20-23.

MANNI, Graziano, I Maestri della scagliola in Emilia Romagna e Marche, Módena, Consorzio fra le Banche Popolari dell'Emilia Romagna Marche, 1997.

MASSINELLI, Anna Maria, Scagliola. L'Arte della pietra di luna, Roma, Editalia, 1997. ROSSINI, Orietta, Ara Pacis, Milán, Electa, 2006.

SAURON, Gilles, L'histoire végétalisée. Ornement et politique à Rome, París, Antiqua e Picard, 2000.

Sistema de Información del Patrimonio Cultural Aragonés (SIPCA) del Gobierno de Aragón [consulta: 06/01/2020], disponible: http://www.sipca.es/censo/7-INMZAR-013-055-005/.html\#.XhMNgdI2q70

WOLTERS, Wolfgang, Architettura e ornamento. La decorazione nel Rinascimento veneziano, Verona, Cierre Edizione, 2007. 
